\title{
Optimal blast wall layout design to mitigate gas dispersion and explosion on a cylindrical FLNG platform
}

\author{
Jingde $\mathrm{Li}^{1, \mathrm{a}}$, Guowei $\mathrm{Ma}^{2, \mathrm{~b}}$, Hong Hao ${ }^{1, \mathrm{c}}$, Yimiao Huang ${ }^{2, \mathrm{~d}}$ \\ ${ }^{1}$ Centre for Infrastructural Monitoring and Protection, \\ School of Civil and Mechanical Engineering, Curtin University, \\ Kent St, Bentley WA 6102, Australia
}

${ }^{2}$ School of Civil, Environmental and Mining Engineering, The University of Western Australia, 35 Stirling Highway, Crawley, WA 6009, Australia

ajingde.li@curtin.edu.au, ${ }^{\mathrm{b}}$ guowei.ma@uwa.edu.au, ${ }^{\mathrm{c}}$ hong.hao@curtin.edu.au,

dyimiao.huang@research.uwa.edu.au

\begin{abstract}
This paper presents a comprehensive safety design of blast wall layout on a cylindrical Floating Liquefied Natural Gas (FLNG) platform. Comparing to the mitigation measure safety gap investigated previously ( $\mathrm{Li}$ et al., 2016a; Li et al., 2016b), blast wall is a better option to be utilized in the congested areas with space limitation. Both of deterministic and probabilistic studies on the cylindrical FLNG platform with and without blast walls subjected to gas dispersion and explosion are conducted. The Computational Fluid Dynamics (CFD) simulation results of more than 120 gas cloud sizes and 16,000 gas explosion overpressures indicate that blast walls are exclusively beneficial for mitigating of flammable gas cloud and explosion overpressure, if the initial gas leak rates are high momentous. A series of different blast wall layouts are designed for the cylindrical FLNG. By taking all uncertainties including different leak rates, leak locations, and gas cloud conditions etc. into account, the optimal blast wall layout with lowest explosion overpressure exceedance frequencies is determined.
\end{abstract}


Keywords: blast wall; gas explosion; gas dispersion; cylindrical FLNG; safety design of FLNG; safety gap

\section{Introduction}

The concept of Floating plant for Liquefied Nature Gas (FLNG) has been proposed since the mid-1970s but made slow progress until May 2011, when Shell decided to proceed with the development of Prelude FLNG. This world's first FLNG vessel, which is $488 \mathrm{~m}$ long, $74 \mathrm{~m}$ wide and weighting 600,000 tons with full loading, has been constructed in 2015 and is now located in the Timor Seak of Australia to provide high production rate of up to 6 million tons per annum of Liquefied Nature Gas (LNG), Liquefied Petroleum Gas(LPG) and condensate(Shell-Global, 2016). Since then a series of FLNG projects have been approved and most are in construction globally.

Comparing to onshore LNG facilities which consisting of costly fixed pipelines, land based liquefaction plant and transportation, FLNG offers more advantages for the exploitation of remote stranded offshore gas reserves. For example, FLNG project has a shorter build period which reduces the construction cost (White and Longley, 2009). In addition, FLNG offers higher efficiency in delivering schedule and completion date by using a shipyard rather than onshore construction with frequent delays (Songhurst, 2016). Operation-wise, FLNG is similar to FPSO, which has the flexibility to be anchored and towed out a different location in the ocean (Suardin et al., 2009). Therefore, presently, many engineers in oil and gas industry regard FLNG as a 'game change' for the development of remote and deep water oil and gas.

However, some weaknesses of the FLNG development also exist. For instance, the maintenance fees of FLNGs are high. Additionally, FLNGs cannot operate in harsh environments, due to the fact that there is a limit on offloading operation arm up to $2.5 \mathrm{~m}$ wave height (Naciri et al., 2007). When typhoons with large waves occur, the ship-shaped 
FLNG cannot provide a stable platform due to the great ratio of its body length to width. Moreover, risk analysis and safety design of FLNGs are not mature at the moment.

In order to address these shortcomings of FLNG, a conceptual design of cylindrical FLNG has been proposed based on the conventionally ship-shape-design FLNG(Li et al., 2016a). The cylindrical FLNG can efficiently minimize the wave induced fatigue loads due to the symmetrically design body shape. Economically, the cost-driving turret and swivel facilities are not required in the circular hull design (Hetland et al., 2009), which reduces the operation and maintenance costs.

However, so far, there are very limited research existing regarding safety design and analysis of the cylindrical FLNGs. (Huang et al., 2016) carried out a case study of Multi-Level Explosion Risk Analysis (MLERA) on the cylindrical FLNG proposed by (Li et al., 2016a). Nonetheless, the case study results merely proved that MLERA method is efficient in saving computational time to identifying the highest level of potential risks, but nothing regarding the safety measure design. In order to investigate the safety measure on gas explosion mitigation, ( $\mathrm{Li}$ et al., 2016a; Li et al., 2016b) designed a series of safety gaps between congested facilities on the cylindrical FLNG topsides. The results of gas dispersion analysis indicated that safety gap is efficient in reducing gas cloud size of a gas leakage in the near field offshore modules, while safety gap increases gas cloud size in the far field of the cylindrical FLNG topside (Li et al., 2016a). In terms of the subsequent gas explosion analysis, beneficial effects of safety gaps on explosion overpressure mitigation were also seen in the near field gas explosions. However, the safety gap could detrimentally enhance explosion overpressure in certain scenarios if an inappropriate safety gap distance ratio was used in the far field explosion design. It was worth noting that the determination of such balanced safety gap distance ratio was not explicit, and the investigation was based on a 
deterministic method. Furthermore, in (Li et al., 2016b)'s study, the safety gaps were designed to separate the congested modules exclusively in the North-South direction as there was sufficient space in such direction, whereas the available open space in the East-West direction was limited.

Under such circumstances, blast wall turns out to be a more feasible safety measure in the space-limited East-West direction. Blast wall, which provides protection to restrict the spread of flammable fuel-air cloud and control the generation of turbulence and explosion waves from neighboring modules, has been designed and generally used as one of the efficient explosion mitigating approaches in the oil and gas industry(Syed et al.; Kang et al., 2016). Blast walls could be installed very close to or are part of the explosion protecting targets/temporary refuge (HSE, 2006). In other words, there is little space limitation on blast wall's application. Therefore, instead of safety gap, blast wall is chosen in this study to investigate its explosion mitigation effect on the cylindrical FLNG platform in the East-West direction.

There have been an extensive amount of studies regarding the structural analysis and design of blast walls (Louca et al., 2004; Langdon and Schleyer, 2005, 2006; Schleyer et al., 2007). However, most studies were about the blast wall material and structural response analysis, while there is very little concern about the overpressure consequences of the arrangement design of blast wall. Moreover, the existing offshore applications of blast walls were tend to be in some traditional structures (Louca et al., 1996; Boh et al., 2007; Sohn et al., 2013; Kang et al., 2016), but no research has been done on the state-of-the-art offshore structure - FLNG, let alone the cylindrical-shaped FLNG.

In this paper, the same cylindrical FLNG platform investigated previously (Li et al., 2016a), has been utilized. Comparing to the deterministic study of safety gap, both of worst-scenario 
and probabilistic studies on a series of different blast wall layout are carried out, more variabilities are considered. The widely-accepted and highly-validated CFD software FLACS (Silvestrini et al., 2008; Hansen et al., 2010; Li et al., 2014; Hansen and Johnson, 2015) is employed to perform gas dispersion and explosion simulations. Overall, the risk analysis is composed of 120 gas dispersion simulations with different variables including 4 varying leakage rates, 2 opposite leakage directions, 3 different gas release locations, 4 sets of blast wall layout designs plus the original platform configuration without blast walls. In terms of the investigation of gas explosion safety, about 200 monitor points are assigned to record the overpressures in each gas explosion simulation. Therefore, over 16,000 gas explosion simulation results are accounted by considering all variables, such as different gas cloud coverages and ignition locations, in the overpressure mitigating design of blast wall layouts.

\section{Geometry of the Cylindrical FLNG platform in FLACS}

The PRICO® technology-designed FLNG units (Black\&Veatch, 2016) are used on the cylindrical FLNG topside. The layout of all modules including dehydration and mercury removal facilities, compressors and liquefaction trains, etc. is designed in detail as shown in Figure 1. The order of these 12 modules is retained the same as that in the ship-shaped FLNG, except that a U-shape pipe rack is used to connect all modules. It is important to note that the turret area commonly used in the ship-shaped FLNG is eliminated in this cylindrical hull (Li et al., 2016a), and the living quarter and workshop is located in the far end of platform with a certain distance away other modules.

The dimension of each topside module is $30 \mathrm{~m}$ wide and $40 \mathrm{~m}$ long, all main structural components of these modules are converted into boxes and cylinders in the geometry modelling by using the pre-processor CASD of FLACS (Gexcon, 2015). The total number of the simplified components is 72,576. The experimentally calibrated sub-grid models of 
FLACS are used to account for the influence of small objects, while large objects and walls are represented on-grid in the porosity calculation of FLACS.

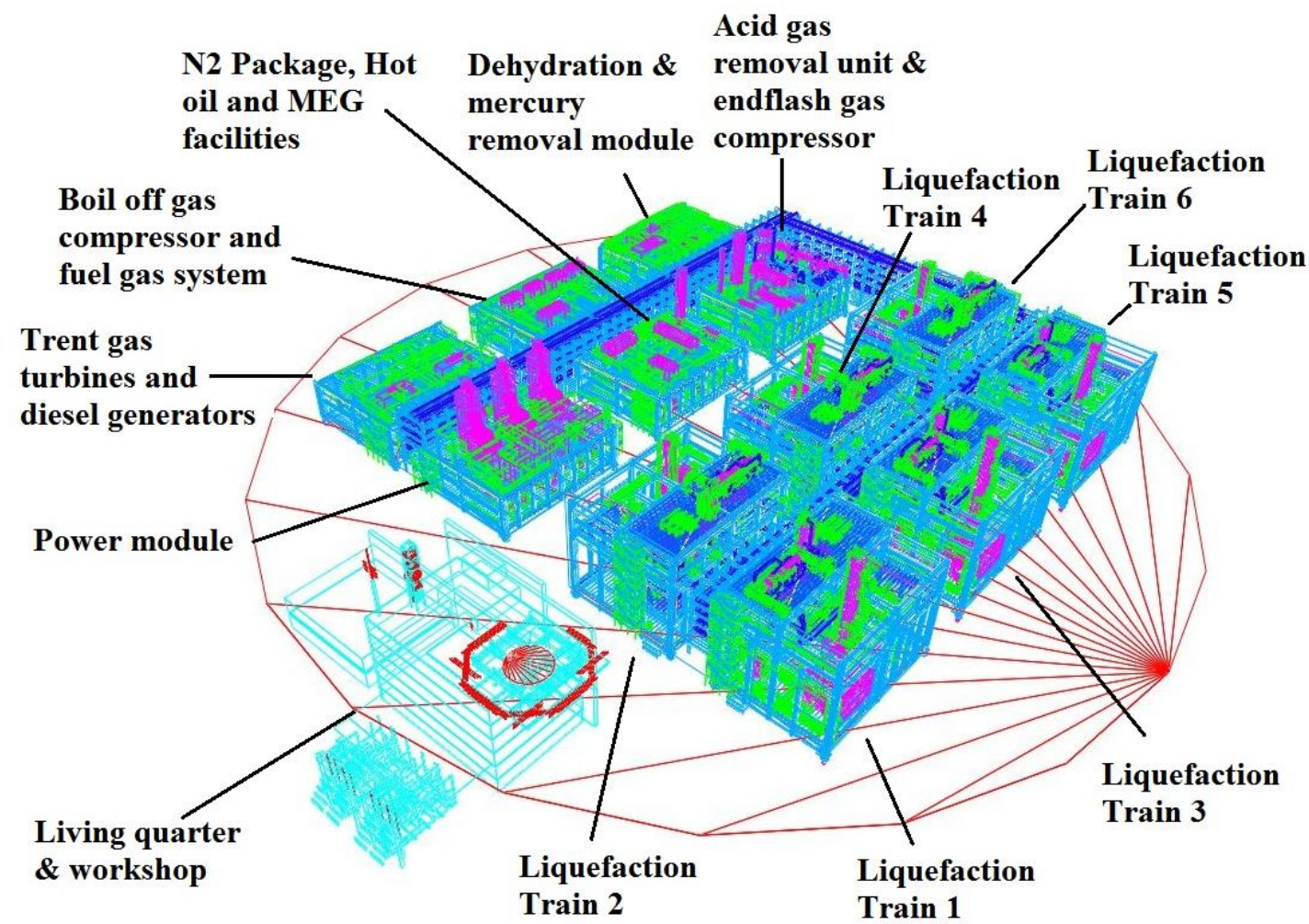

Figure 1 Wireframe of the cylindrical FLNG platform geometry in FLACS

\section{Input of gas dispersion and explosion simulation}

The major variations in the CFD simulation and risk analysis include leak rate, leak direction, leak location, gas composition and wind condition. In this study, the investigation into blast wall's explosion mitigating effect is only in East-West direction, and the protection target living quarter, which was investigated and regarded as the area with the highest level of potential risks (Huang et al., 2016), is in the very east side (Figure 2). Therefore, the authors exclusively select west to east wind direction ( $+\mathrm{x}$ coordinate in CASD of FLACS) as the worst wind scenario to examine the gas dispersion of a leakage. The wind speed is fixed as 
$+4 \mathrm{~m} / \mathrm{s}$, and both of east and west leak directions are considered in the gas dispersion simulation.

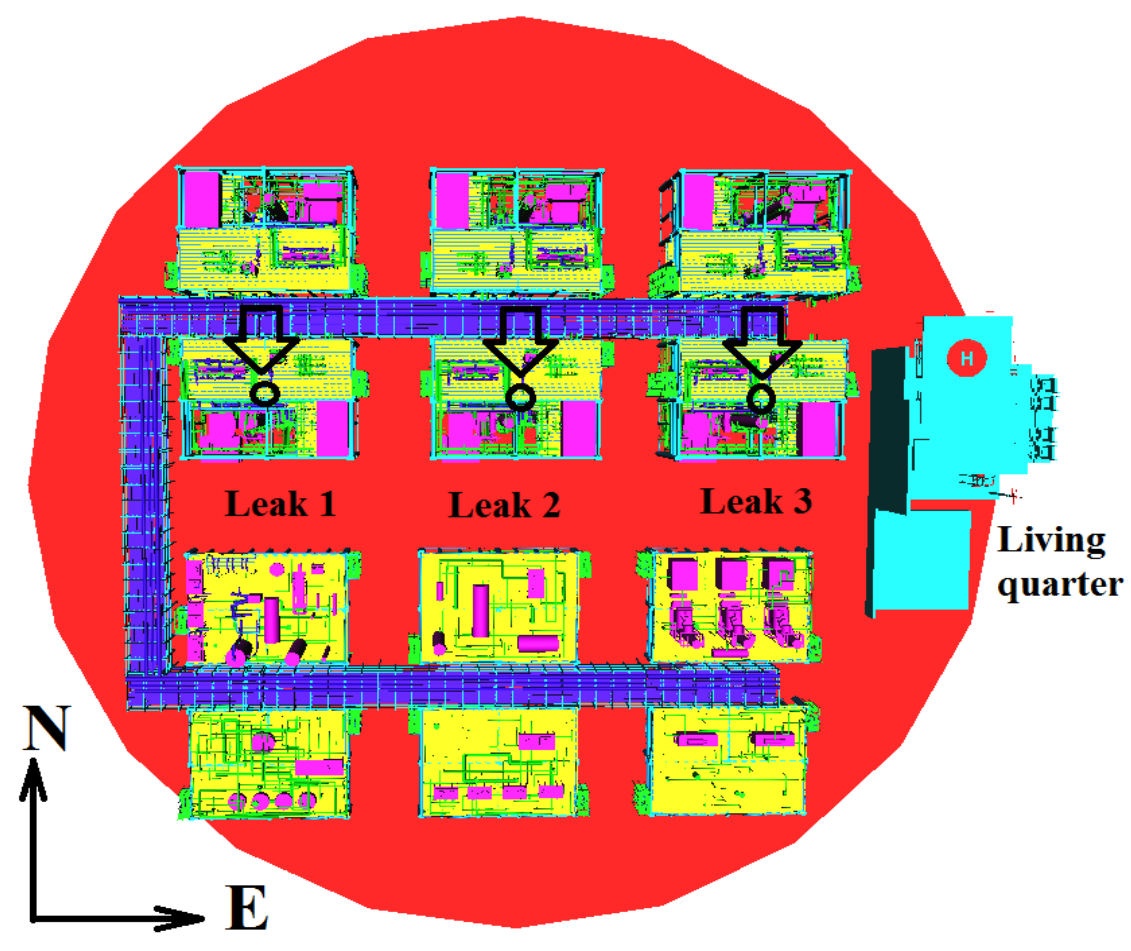

Figure 2 Leak locations on the cylindrical FLNG platform

In terms of the choice of leak location, three critical locations in the liquefaction train modules (as seen in Figure 2) are determined, which is based on the conclusion of previous work (Li et al., 2016a) that gas leaks in these more congested regions are more likely to generate bigger volume of stoichiometric gas clouds and transmit more gas cloud to the far field. Accordingly, the representative leak rates from $0.25 \mathrm{~kg} / \mathrm{s}$ to $96 \mathrm{~kg} / \mathrm{s}$ (Norsok, 2001) for these three leak locations are chosen in the gas dispersion simulations, as seen in Figure 3. The inventory of gas composition inside the cylindrical FLNG are summarized in Table 1. 


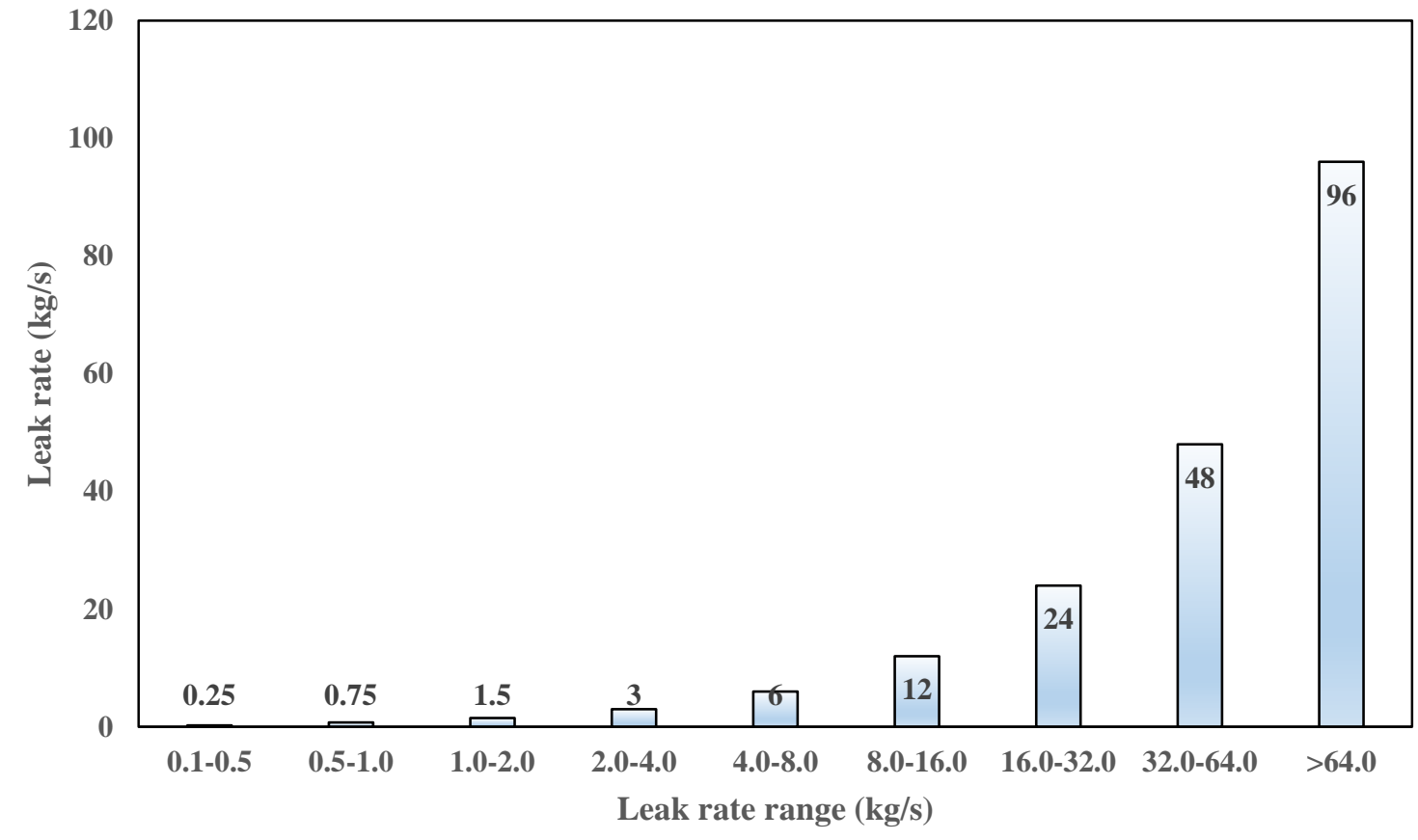

Figure 3 Leak rate data on the cylindrical FLNG platform

Table 1 Gas composition for dispersion and explosion study

\begin{tabular}{|c|c|}
\hline Component & Export gas \\
\hline Methane & $27 \%$ \\
Ethane & $33 \%$ \\
Propane & $15 \%$ \\
Hexane & $19 \%$ \\
$\mathrm{CO}_{2}$ & $6 \%$ \\
\hline
\end{tabular}

\section{Design of blast wall layout}

Figure 4 provides the general overview of the geometry with blast wall installation in front of the congested modules. In FLACS, all structural components are assumed to be unyielding during the entire explosion. In other words, the blast walls remain in place even for gas explosion with extreme overpressures. Therefore, the structural design and analysis of the blast wall are not considered in this study. Instead, the purpose of using blast wall in the CFD simulation is to provide interruption of gas cloud propagation from nearby modules and protection against explosion loads from neighbouring modules. Moreover, this risk analysis is 
aim to investigate the consequences of different gas dispersions and explosions in different congestion and confinement conditions if blast walls are used.

Consequently, as seen in Figure 5, blast walls are designed as barriers directly next to the congested modules to account for different confinement scenarios. Due to the fact that only west to east wind direction is chosen to investigate the high risk region - living quarter, blast walls are mainly installed on the east side of the module to block the flammable gas cloud propagating from more congested areas in west. Four essential blast wall layouts are designed, the red colour represents blast wall in the plane view of the cylindrical FLNG platform.

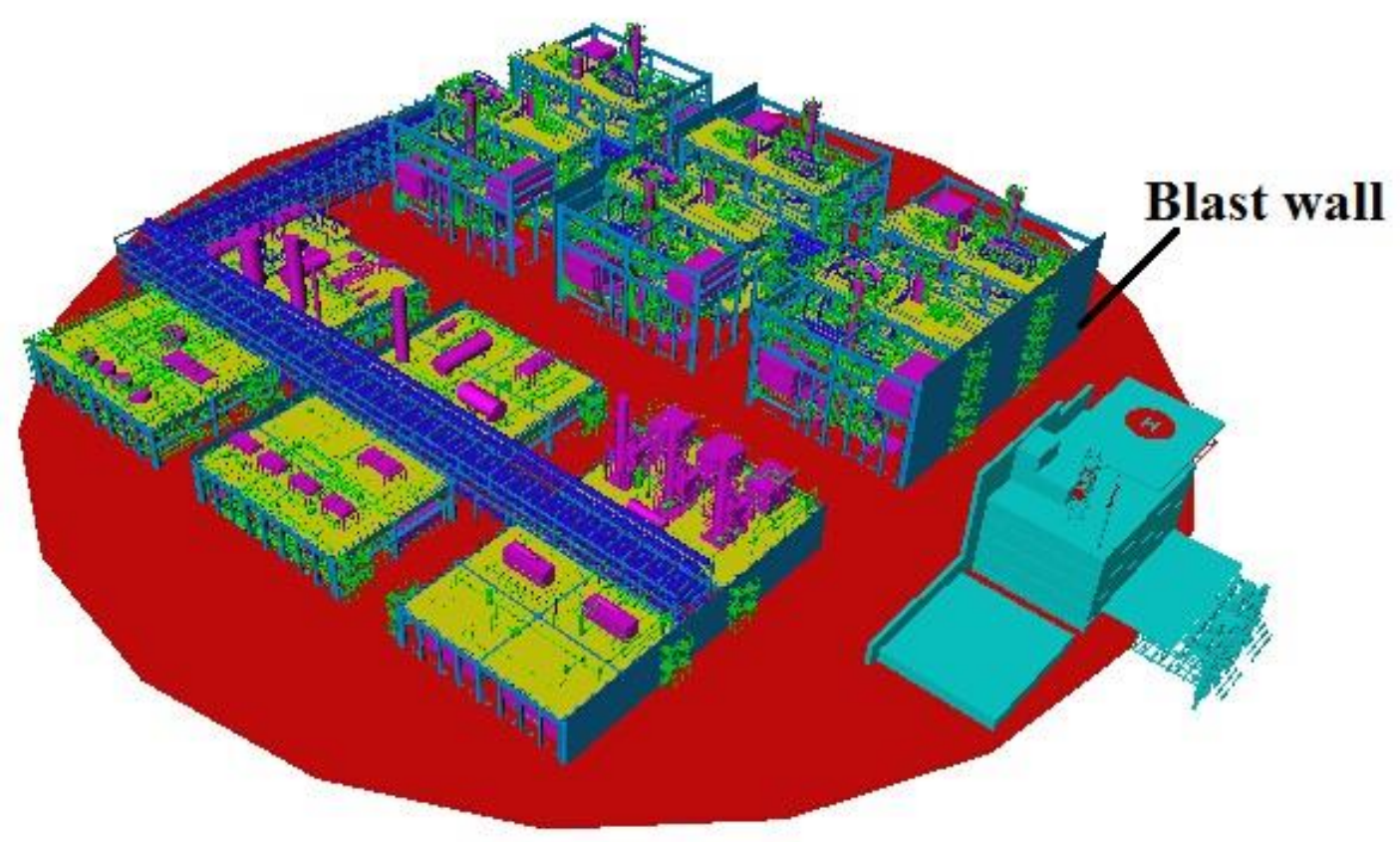

Figure 4 Blast wall installed in front of the modules of the cylindrical FLNG 
Design 1. Blast walls on 1 side

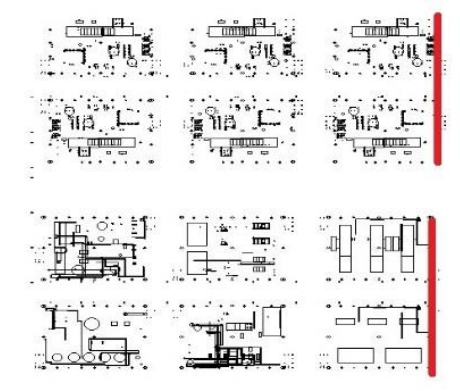

Design 3. Blast walls on 2 sides

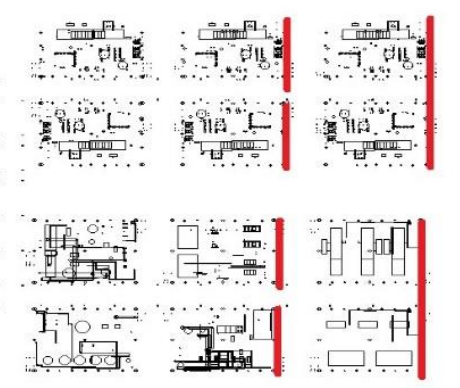

Design 2. Blast walls on 2 sides
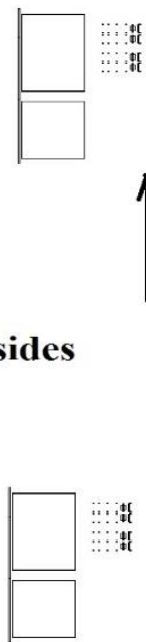

Figure 5 Blast wall layout designs

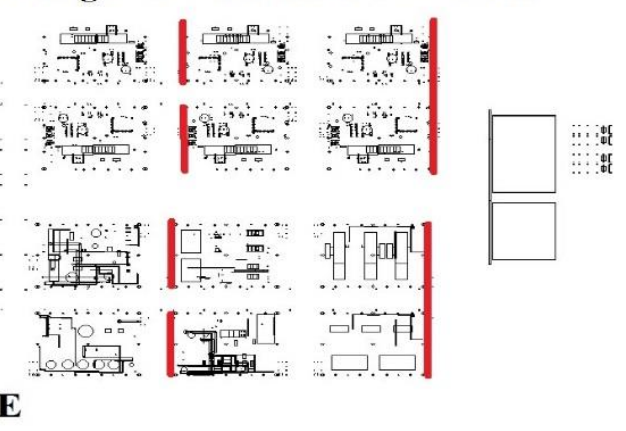

Design 4. Blast walls on 3 sides

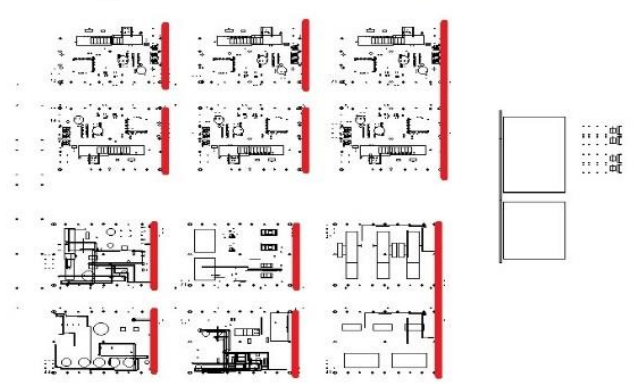

\section{Gas dispersion and gas explosion analysis}

\subsection{Gas dispersion analysis}

\subsubsection{Numerical model and input}

In the gas dispersion analysis, the grid size of $1 \mathrm{~m}$ near the leakage is chosen as FLACS relies on numerous experimentally validated sub-grid models which are in a range of cell sizes around or above 1m (Hansen et al., 2010; Daubech et al., 2013; Kuznetsov et al., 2015; Vyazmina and Jallais, 2016). In addition, it is stated in FLACS guidelines that grids of 1$1.5 \mathrm{~m}$ should be sufficient for offshore modules $>8 \mathrm{~m}$ in height (Gexcon, 2015), while the dimension of the smallest FLNG topside module is $30 \times 40 \times 25 \mathrm{~m}^{3}$, not to mention the entire size of the cylindrical FLNG platform. Therefore, the grid resolution of $1 \mathrm{~m}$ is used for the CFD modelling in this study.

For the specific leak rate, the effective cross-section area of a leak outlet in FLACS is determined as: 


$$
m^{\prime}=\rho \cdot u \cdot A
$$

Where $m^{\prime}$ is the leak/flow rate, $u$ is the velocity at the outlet, $\rho$ is the gas density and $A$ is outlet areas.

The gas density of gas composition shown in Table 1 is $1.6 \mathrm{~kg} / \mathrm{m}^{3}$, hence, for a representative low-medium momentum leak rate of $6 \mathrm{~kg} / \mathrm{s}$, and outlet leakage velocity of $5 \mathrm{~m} / \mathrm{s}$, the effective cross-section area of leak outlet is calculated as $0.75 \mathrm{~m}^{2}$. Consequently, the theoretical grid size of the leak outlet is determined as $0.87 \mathrm{~m}$ (i.e. the square root of $0.75 \mathrm{~m}^{2}$ ), which is smaller than the initial choice of $1 \mathrm{~m}$ grid size near leakage. In order to model small leakage area size $\left(<1 \mathrm{~m}^{2}\right)$, the overall CFD simulation time would be tremendously increased if the refinement of the grid resolution is performed. For example, the required CPU-time will increase 16 times when increasing grid resolution by a factor of two $\left(=2^{3+1}\right)$ due to 3 spatial dimensions combined with the time step being proportional to the grid sizes (Hansen and Johnson, 2015). Moreover, for gas leakages with small leak rates on the large-size cylindrical FLNG platform, the generated steady state gas cloud size is too small that it could be confined in just one module (Li et al., 2016a). After the ignition of such small size gas cloud, the subsequently induced explosion overpressures are not big enough to threaten neighboring modules (e.g. the living quarter with a safety gap away other congested modules)

Therefore, the low momentum leak rate case $(\leq 6 \mathrm{~kg} / \mathrm{s})$ is not considered in this study. 4 categories of leak rates, which are $12 \mathrm{~kg} / \mathrm{s}, 24 \mathrm{~kg} / \mathrm{s}, 48 \mathrm{~kg} / \mathrm{s}$ and $96 \mathrm{~kg} / \mathrm{s}$, have been taken into account to study the possible gas cloud volume and explosion overpressure buildup in all blast wall layout designs. In addition to the variations of 3 leak locations and 2 leak orientations, Table 2 summarizes the overall leak cases. The gas monitor region covers all the modules on the cylindrical FLNG platform, as seen in Figure 6. 


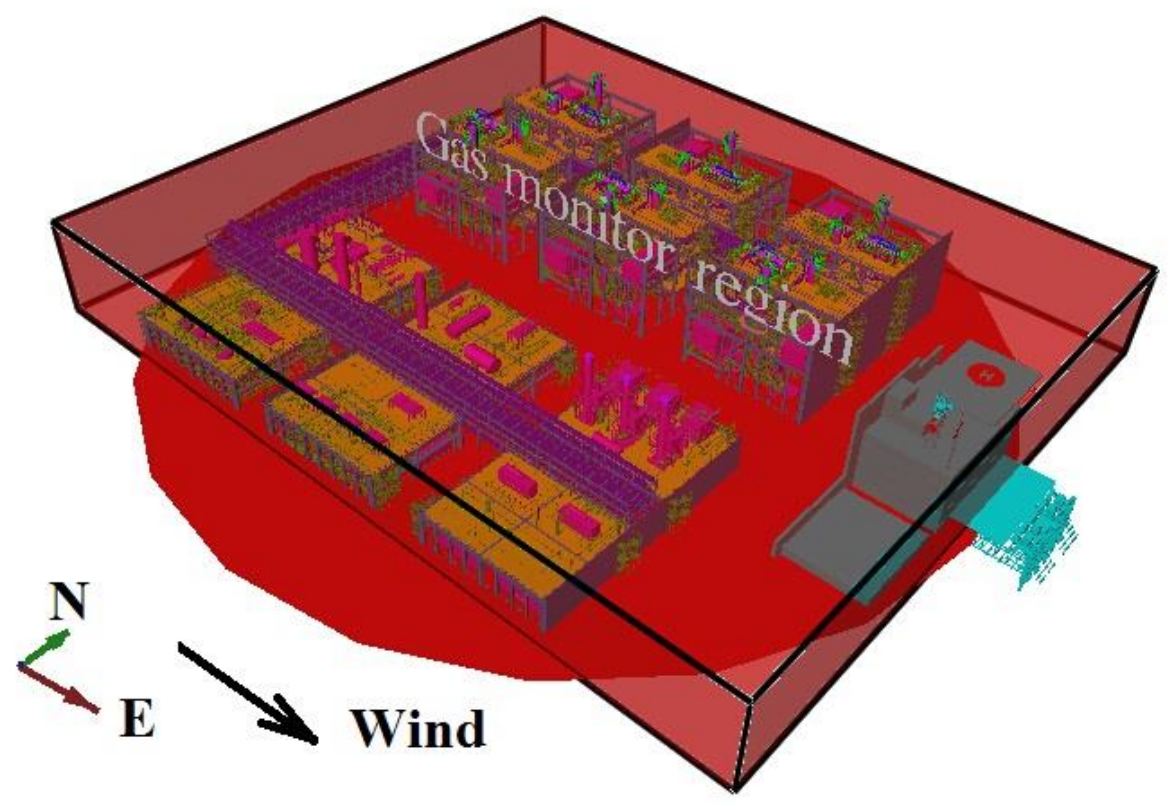

Figure 6 Gas cloud monitor region on the cylindrical FLNG platform

Table 2 Various leak cases determined for dispersion study

\begin{tabular}{|c|c|c|c|c|c|}
\hline Case & $\begin{array}{c}\text { Wind } \\
\text { direction }\end{array}$ & $\begin{array}{c}\text { Wind } \\
\mathbf{s p e e d} \\
(\mathbf{m} / \mathbf{s})\end{array}$ & $\begin{array}{c}\text { Leak rate } \\
\mathbf{( k g / s )}\end{array}$ & Leak position & Leak orientation \\
\hline 1 & West to East & 4 & $12,24,48,96$ & West end & $\begin{array}{c}\text { Along and opposite } \\
\text { wind } \\
\text { Along and opposite } \\
\text { wind }\end{array}$ \\
3 & West to East & 4 & $12,24,48,96$ & Middle & $\begin{array}{c}\text { Along and opposite } \\
\text { wind }\end{array}$ \\
\hline
\end{tabular}

The volume of equivalent stoichiometric gas cloud in the gas monitor region is recorded as Q9, which is widely used in Quantitative Risk Analysis and is expected to give similar explosion loads as the original gas cloud. $Q^{9}$ is defined as (Gexcon, 2015):

$$
\left.Q 9=\frac{\sum_{1}^{n} V_{i}\left[V_{e}\left(E R_{i}\right)-4\right] \cdot E R_{f a c}\left(E R_{i}\right)}{\max \left\{\left[V_{e}(E R)-1\right] \cdot E R_{f a c}(E R): E R_{L F L} \leq E R \leq E R_{U F L}\right.}\right\}
$$


Where the summation $i=1, \ldots, n$ is all numerical control volumes inside the gas monitor region, $V_{i}$ is the non-blocked open volumes of fluid flow, $V_{e}(E R)$ is the volume ratio function of equivalence ratio $(E R)$, and the $E R$ is a measure of the concentration of fuel compare to the stoichiometric concentration. $V_{e}(E R)$ and $E R$ are defined as

$$
\begin{aligned}
& E R=\frac{F / O}{(F / O)_{\text {stoichiomeric }}} \\
& V_{e}=\frac{V_{\text {burnt }}}{V_{\text {unburnt }}}
\end{aligned}
$$

Where $F / O$ is the ratio of fuel to oxygen, $V_{\text {burnt }}$ is the volume of burnt fuel-air mixture, and $V_{\text {unburnt }}$ is the fuel-air mixture volume before combustion.

The $E R$ in Equation 2 is set with a value between the Lower Flammability Limit ( $L F L)$ equivalence ratio and Upper Flammability Limit $(U F L)$ equivalence ratio (i.e. $E R_{L F L} \leq E R \leq$ $\left.E R_{U F L}\right)$. The function of $E R_{f a c}(E R)$ is a laminar burning velocity profile, which is defined as:

$$
E R_{f a c}\left(E R_{i}\right)=\frac{S_{L}\left(E R_{i}\right)}{\max \left\{S_{L}(E R): E R_{L F L} \leq E R \leq E R_{U F L}\right\}}
$$

Where $S_{L}$ is the laminar burning velocity corrected for lame wrinkling/ Lewis number effects.

\subsubsection{Results and discussion of gas dispersion simulations}

Firstly, the deterministic study of the worst gas dispersion scenarios is conducted. In the previous study(Li et al., 2016a), it was concluded that the gas leakage occurring in more congested regions results in bigger stoichiometric gas clouds. Therefore, here, the gas dispersion simulations are carried out in the liquefaction train modules located in the middle of the FLNG topside, where the congestion ratios are the highest. The leak rates are set as 
$48 \mathrm{~kg} / \mathrm{s}$, leak directions are assigned along with the wind direction from west to east, and leaks are placed on the ground in the middle module.

Figure 7 depicts the output of four gas dispersion simulations for gas releases in different blast wall layouts. $Q 9$ is recorded within the gas flammable range of $E R_{L F L}=0.5$ to $E R_{U F L}=2.5$. The simulation time is terminated at 210 s when the stoichiometric gas cloud reaches the steady state.

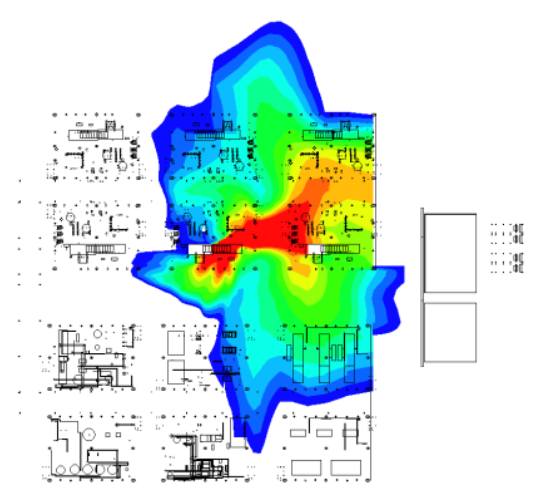

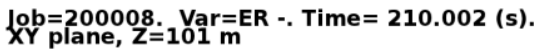

(a) Design 1. Blast walls on 1 side

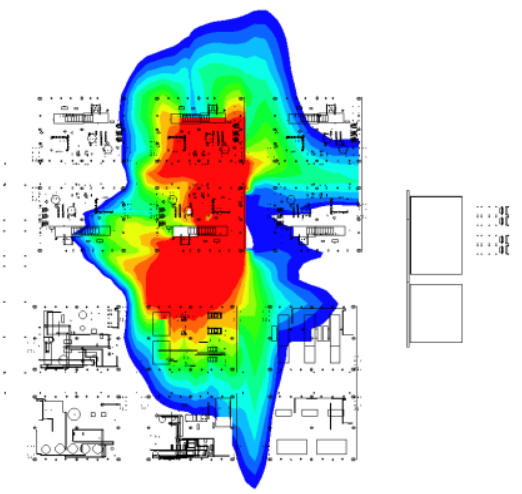

lob $=200008$.
XY plane, $Z=101 \mathrm{~m}$

(c) Design 3. Blast walls on 2 sides

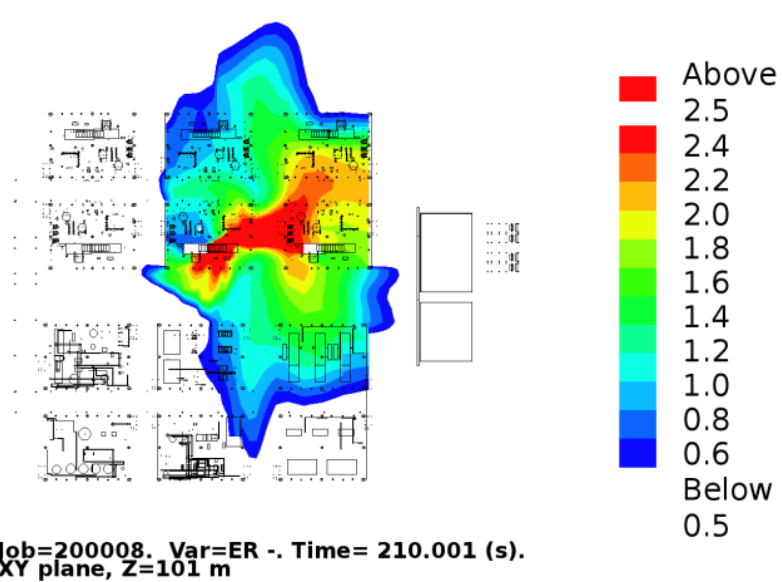

(b) Design 2. Blast walls on 2 sides

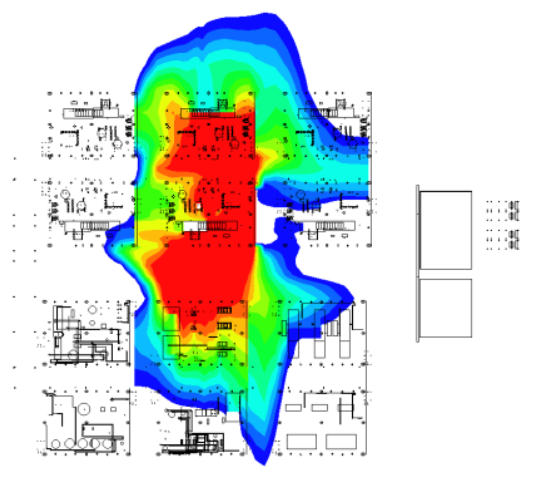

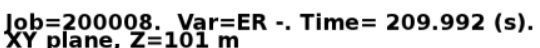

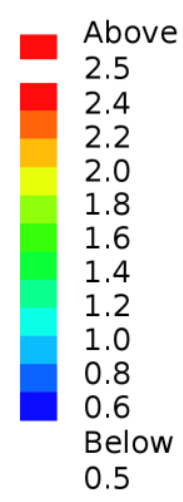

(d) Design 4. Blast walls on 3 sides

Figure 7 Gas dispersion simulations for leaks in the middle of different blast wall layouts

For blast wall design layout 1 and design layout 2, it is seen in Figure 7 (a) and (b) that blast walls in the east end effectively restrain the propagation of the gas cloud. In addition to these east end walls, extra installed blast walls in other modules in design layout $3 \& 4$ (as seen in Figure 7 (c) and (d)), further prevent the cloud size propagating to the living quarter. 
Meanwhile, the gas clouds become more concentrated in the middle modules of the design layout $3 \& 4$. The richer gas concentrations in these two configurations result in higher $E R$ going beyond the upper flammability limit (e.g. $E R_{U F L}=2.5$ ), which on the other hand reduces the overall stoichiometric gas cloud size. To summarize, the results of this worst-scenario investigation indicate that extra blast wall is beneficial in confining total gas cloud size.

However, the comparison above is only carried out based on 4 worst-scenario cases (highmomentum leaks) of the overall 120 scenarios. In order to investigate all leak rate cases thoroughly, cases from Table 2 for all blast wall layouts are modelled by using FLACS. The stoichiometric gas cloud size of each case is recorded at the time when the gas dispersion simulation reach steady state. By sorting the gas cloud size from small to large and giving equal leak frequencies to all leakage cases, the exceedance curves of gas cloud sizes within the gas monitor region are summarized in Figure 8.

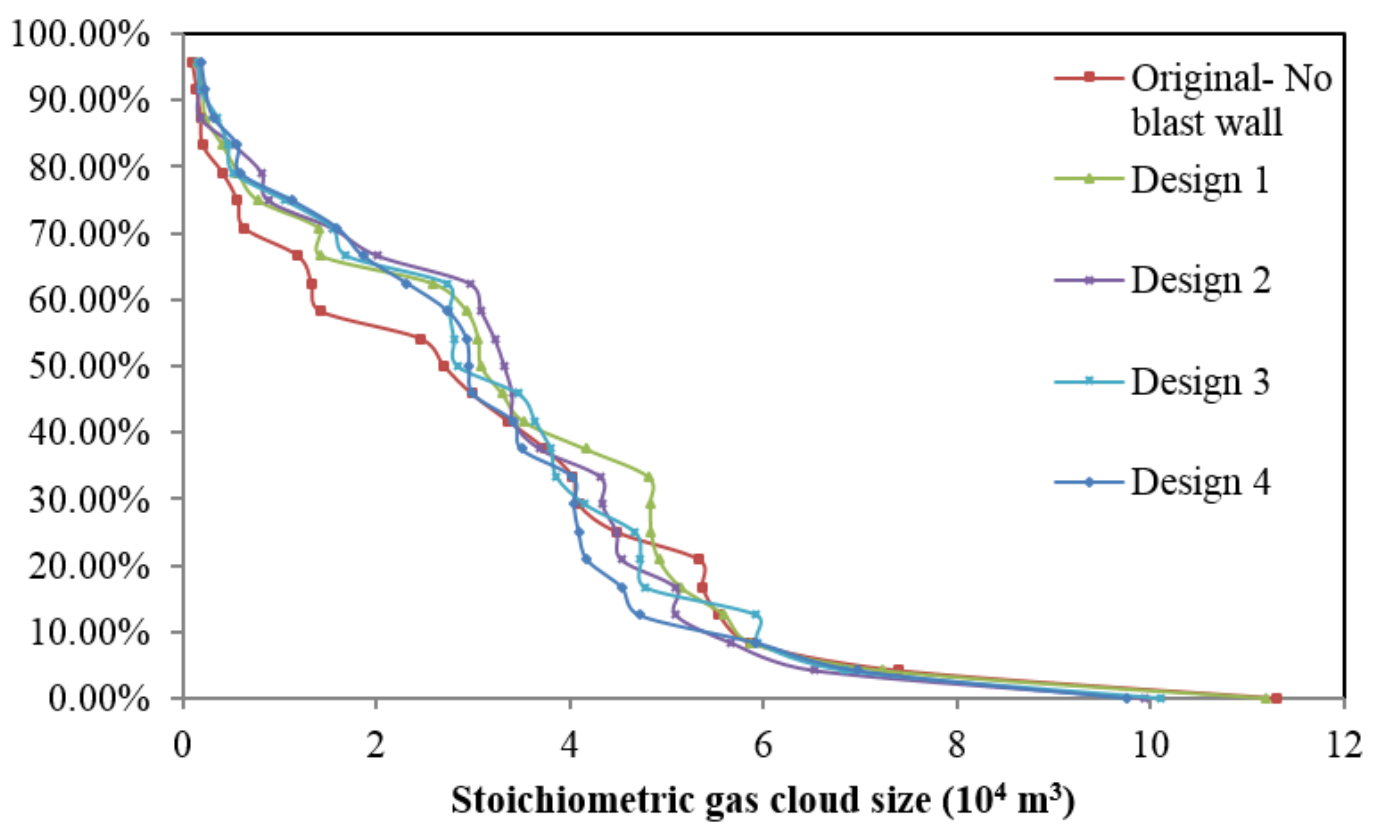

Figure 8 Exceedance curve of gas cloud sizes for all leak rate scenarios 


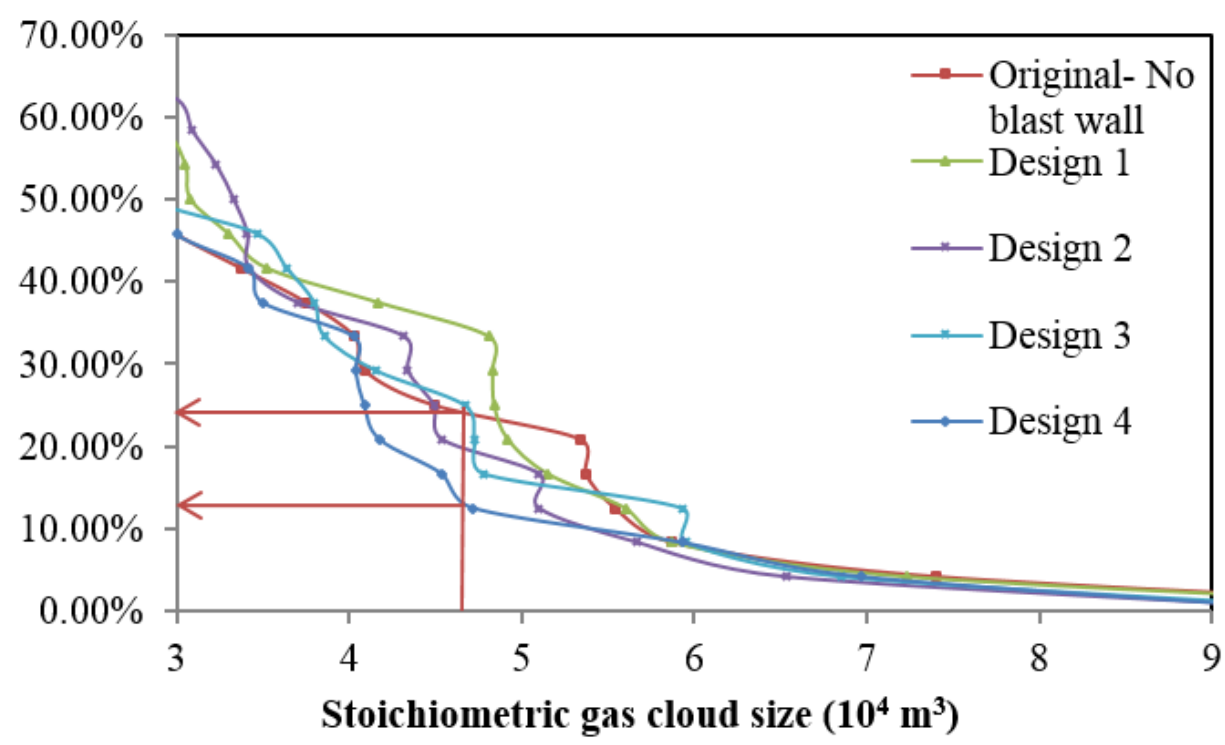

Figure 9 Exceedance curve of gas cloud sizes over $3 \times 10^{4} \mathrm{~m}^{3}$ for different leak rate scenarios

As seen in Figure 8, for stoichiometric gas cloud size smaller than $3 \times 10^{4} \mathrm{~m}^{3}$, all blast wall designs have greater frequencies compared to the original cylindrical FLNG without blast wall. In other words, these blast walls on the FLNG platform have higher chances to induce larger gas clouds, which is due to the increase of confinement in these congested modules. However, it is worth mentioning that all these enlarged gas clouds only exist in the cases where leakages are at leak rates of $12 \mathrm{~kg} / \mathrm{s}$ and $24 \mathrm{~kg} / \mathrm{s}$. For these low leak rate gas dispersions, the corresponding gas clouds are much smaller than that in $48 \mathrm{~kg} / \mathrm{s}$ and $96 \mathrm{~kg} / \mathrm{s}$ gas release cases, even though the gas cloud sizes are enlarged to some extent. Precisely, for a liquefaction train with dimension of $30 \times 40 \times 25 \mathrm{~m}^{3}$, the gas cloud sizes equal or smaller than $3 \times 10^{4} \mathrm{~m}^{3}$ by gas leaking with rates of $12 \mathrm{~kg} / \mathrm{s}$ and $24 \mathrm{~kg} / \mathrm{s}$ will be mainly retained in the liquefaction train itself. It is not expected to see the subsequent explosion overpressures of the $12 \mathrm{~kg} / \mathrm{s}$ and $24 \mathrm{~kg} / \mathrm{s}$ cases after ignition are sufficient to threaten structures and people in far field.

By contrast, for the gas dispersions at leak rate $48 \mathrm{~kg} / \mathrm{s}$ and $96 \mathrm{~kg} / \mathrm{s}$, a distinct tendency of cloud size restriction due to blast wall is seen in Figure 9. It is shown that most of the blast 
wall layouts possess lower frequencies at the same stoichiometric gas cloud size. For instance, for gas cloud size of $4.7 \times 10^{4} \mathrm{~m}^{3}$, the exceedance probability in blast wall layout No. 4 is only $12 \%$ while it is $24 \%$ for the original configuration without blast walls. That is, if the exceedance probability is read at $24 \%$, the gas cloud size of $4.7 \times 10^{4} \mathrm{~m}^{3}$ could be reduced to $4.1 \times 10^{4} \mathrm{~m}^{3}$ by using the blast wall layout No. 4 .

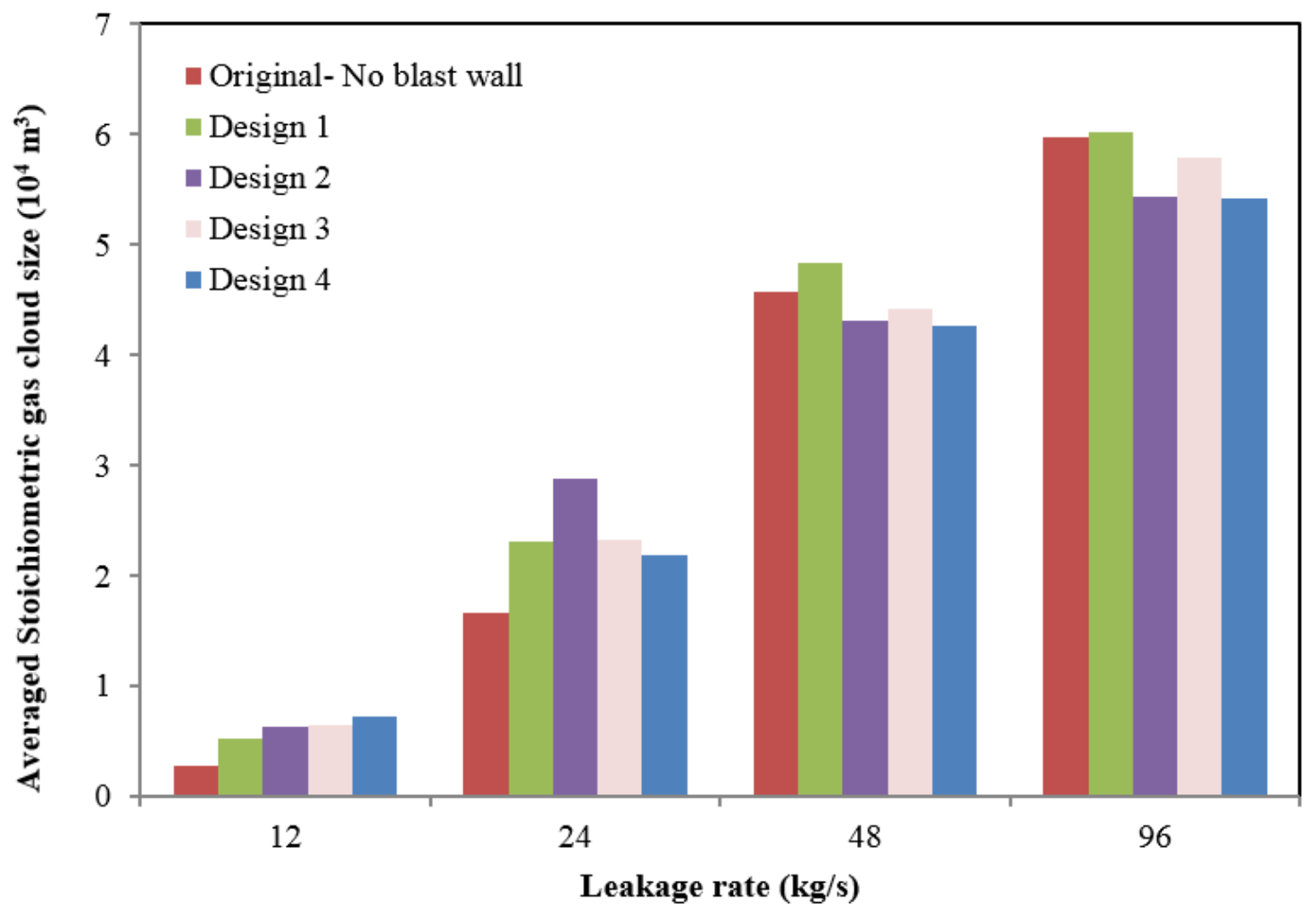

Figure 10 Averaged gas cloud size for different leak rate scenarios

In order to have a straightforward understanding of the gas cloud mitigating effect of blast walls at different leak rates, the stoichiometric gas clouds at all locations are averaged and displayed in Figure 10. It is seen in the figure that the blast wall only play active role in gas cloud reducing when leakage rate goes over $48 \mathrm{~kg} / \mathrm{s}$. Under such condition, gas dispersions occurring on the cylindrical FLNG platform with blast wall layout No. 2 and layout No. 4 have the smallest stoichiometric gas cloud sizes. However, blast wall layout No. 2 is the most disadvantageous configuration if the leak rate is $24 \mathrm{~kg} / \mathrm{s}$. Overall, blast wall layout No. 4 is the 
optimal design amongst all the configurations in terms of overall gas cloud size in all gas dispersion cases.

In summary of all data of the exceedance curves and the averaged gas cloud size chart, it is concluded that blast walls could be meaningless and even detrimental for gas dispersions with low leak rates $(\leq 24 \mathrm{~kg} / \mathrm{s})$. However, for high-momentum leakages (i.e. leak rate $>24 \mathrm{~kg} / \mathrm{s}$ ), an appropriately designed blast wall system can effectively reduce the gas cloud size. Comparing to these low leak rate $(\leq 24 \mathrm{~kg} / \mathrm{s})$ gas dispersions with gas cloud sizes below $3 \times 10^{4} \mathrm{~m}^{3}$, the high momentous leak cases with leak rates of $48 \mathrm{~kg} / \mathrm{s}$ and $96 \mathrm{~kg} / \mathrm{s}$ result in much larger gas clouds propagating to neighbouring modules or even far field. Ignitions to these large gas clouds can lead to more severe consequences to living quarter in far field. Therefore, blast wall designs to these large gas cloud scenarios are more meaningful since the blast walls are more efficient in reducing high momentous leak cases' gas clouds. Accordingly, the further investigation into gas explosion is required and carried out in the following section.

\subsection{Explosion analysis}

\subsubsection{Numerical model and input}

All gas dispersion data above are utilized in the risk analysis of the cylindrical FLNG subjected to gas explosion. As seen in Figure 11, the gas clouds are situated in 4 different locations covering the entire platform so that the overall gas explosion consequences for all modules could be analyzed. For all gas clouds, the plan view dimension is fixed as $100 \times 80$ $\mathrm{m}^{2}$ so that at least 4 modules are covered by one gas cloud, while the height of cloud is varying according to the gas dispersion simulation results obtained previously. For each gas explosion simulation, the gas cloud is ignited in the ground center of one module, where the congestion ratio is the highest. 
For gas explosion simulation on the cylindrical FLNG platform, about 200 monitor points are assigned on the ground to record the explosion overpressures. In addition, by taking all variables of 4 different gas cloud coverages, and 4 different ignition locations of each gas cloud into account, about 3200 explosion overpressures are monitored for each blast wall layout design. Eventually, by multiplying the total number of 4 different blast wall layouts plus the original layout without blast wall, more than 16,000 overpressures are recorded in this probabilistic study of gas explosion.

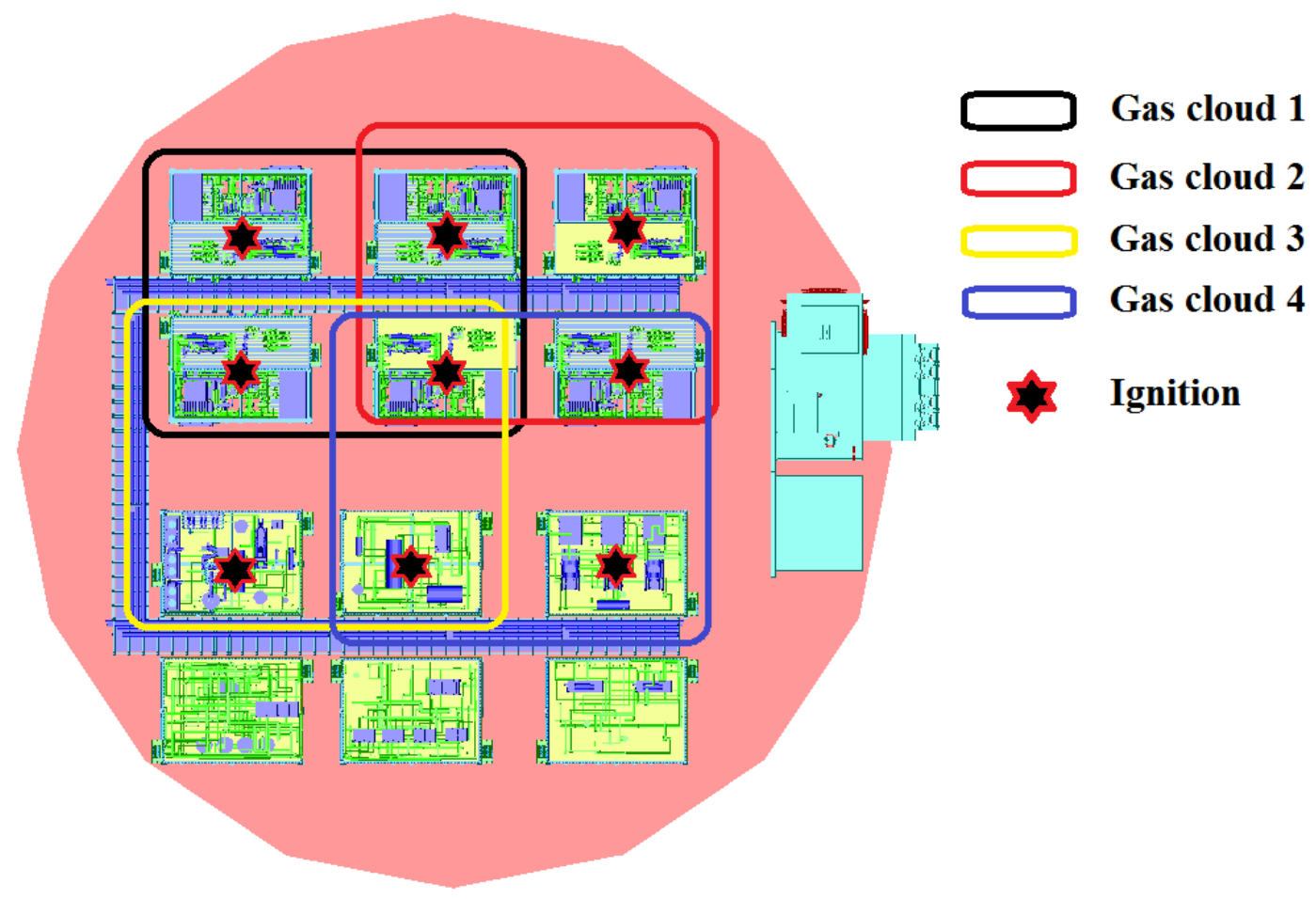

Figure 11 Overview of gas cloud coverage and ignition locations

\subsubsection{Results and discussion from explosion simulations}

\subsubsection{The integral analysis of gas explosion}

Figure 12 shows the overpressure output of one of the gas explosion simulations for the original FLNG platform without blast walls. The gas cloud size utilized in this explosion simulation is corresponding to the dispersion simulation with the leak rates of $48 \mathrm{~kg} / \mathrm{s}$ in Section 5.1.2. The ignition is in the center of the gas cloud located in the east end of the 
platform. The overpressures are displayed in range of 0.1 to 2 bar, the red color represents the maximum overpressure. It is seen that the gas explosion blast is spreading from the ignition center to all surrounding objects, the maximum overpressures are observed in congested region near the edge of the gas cloud, and the living quarter is subjected to about 1.0 bar overpressure.

The comparison between the original platform and the blast wall layouts is then conducted and shown in Figure 12 and Figure 13. The blast wall layout No. 1 in Figure 13 (a) effectively reduce the overpressure from 1.0 bar to 0.6 bar near the living quarter, while an extra blast wall installed in the layout No. 2 in Figure 13 (b) restricts more overpressures in the neighboring area of the living quarter. However, the overpressure concentrations are seen near the blast walls, over 2 bar overpressure could be reflected to the confined modules from the blast walls unavoidably.

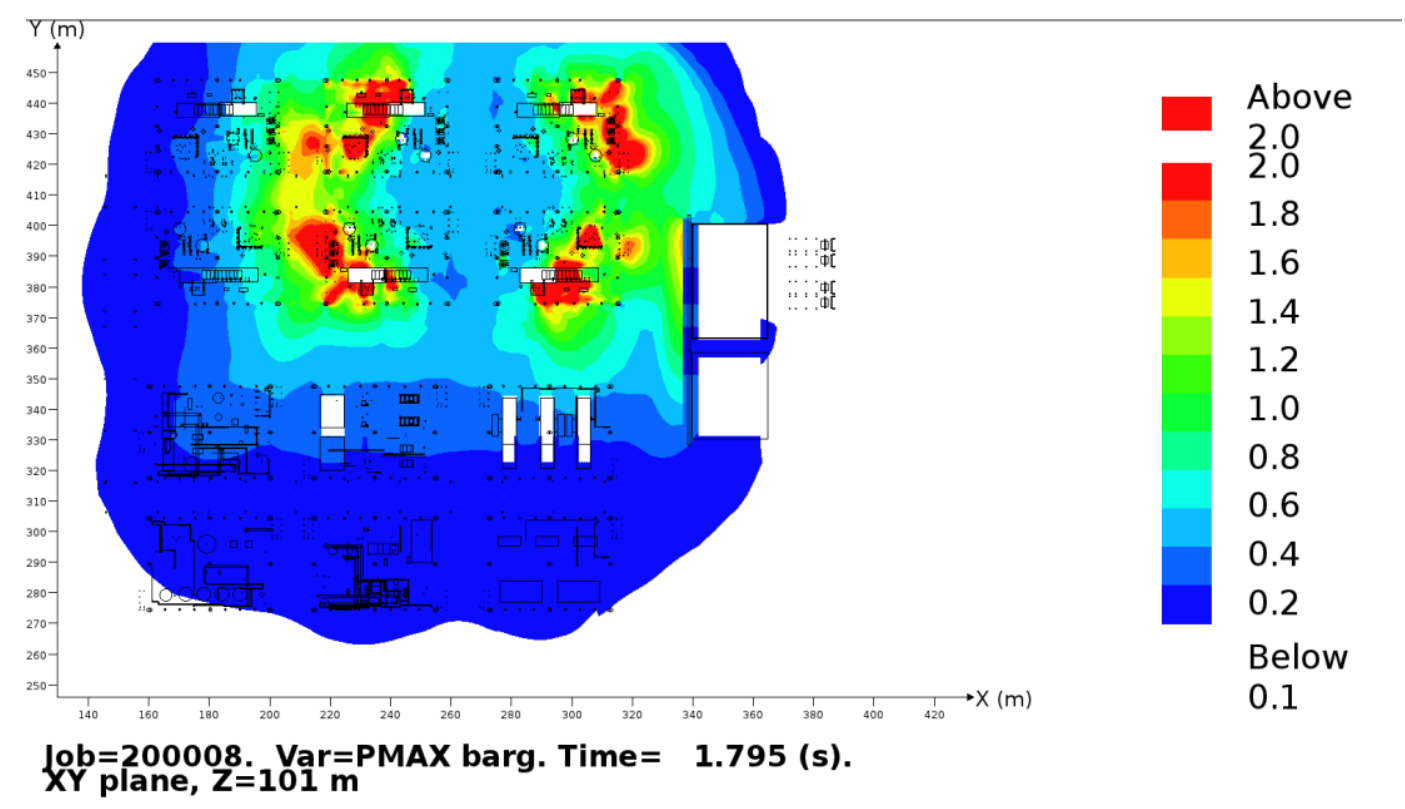

Figure 12 Gas explosion simulation of the original platform without blast wall configurations 


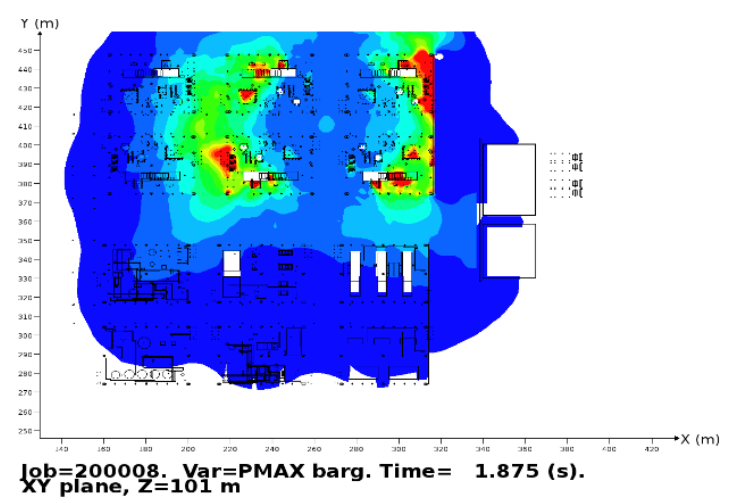

(a) Design 1. Blast walls on 1 sides

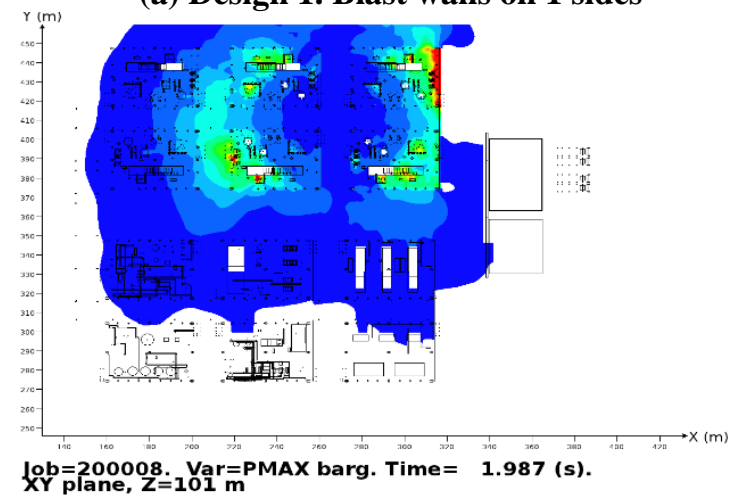

(c) Design 3. Blast walls on 2 sides

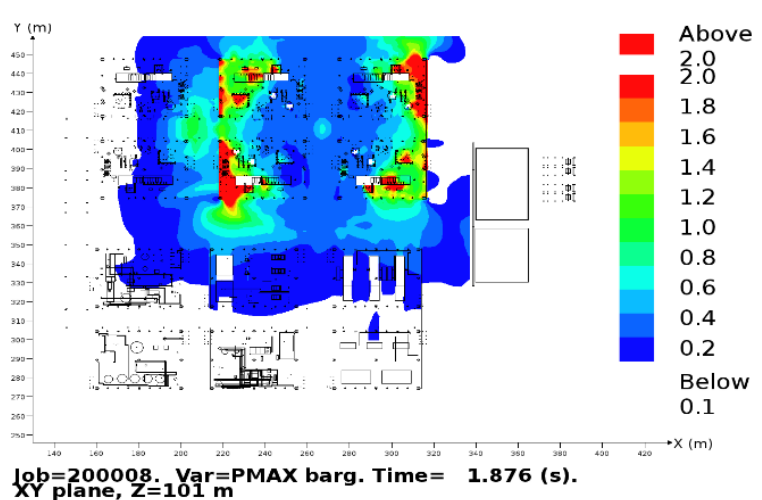

(b) Design 2. Blast walls on 2 sides

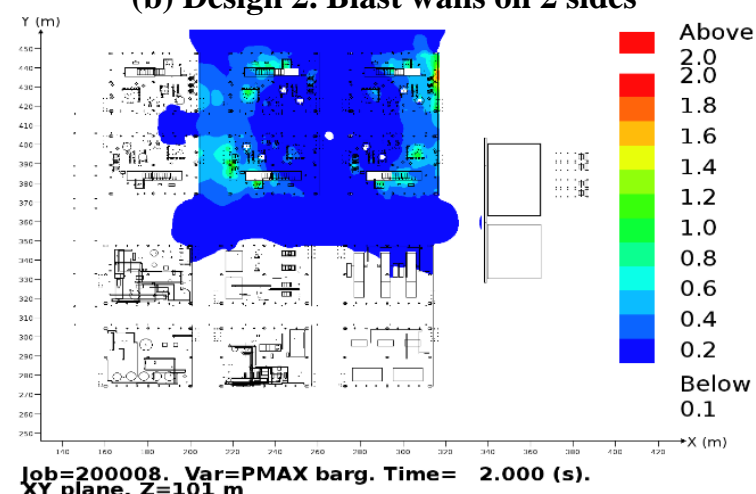

(d) Design 4. Blast walls on 3 sides

Figure 13 Gas explosion simulations of different blast wall layouts

The issue of overpressure concentration is considerably addressed by adding additional blast walls, as seen in Figure 13 (c) and (d). Precisely, the living quarter is subjected to lower overpressures since blast walls in layout No. 4 more efficiently mitigate overpressures from 1.0 bar to below 0.1 bar (Figure 13 (d)). However, the above comparison of these design is merely the deterministic analysis on gas explosion, which is corresponding to the worstscenario cases in previous section of gas dispersion analysis.

In order to probabilistically consider all gas dispersion output as input in the gas explosion simulations, these 120 different gas clouds obtained previously are ignited in the gas explosion simulations of this section. The exceedance curves of gas explosion simulations are summarized in Figure 14. Equal frequencies are allocated to all monitored overpressures, which are sorted from small to large. 


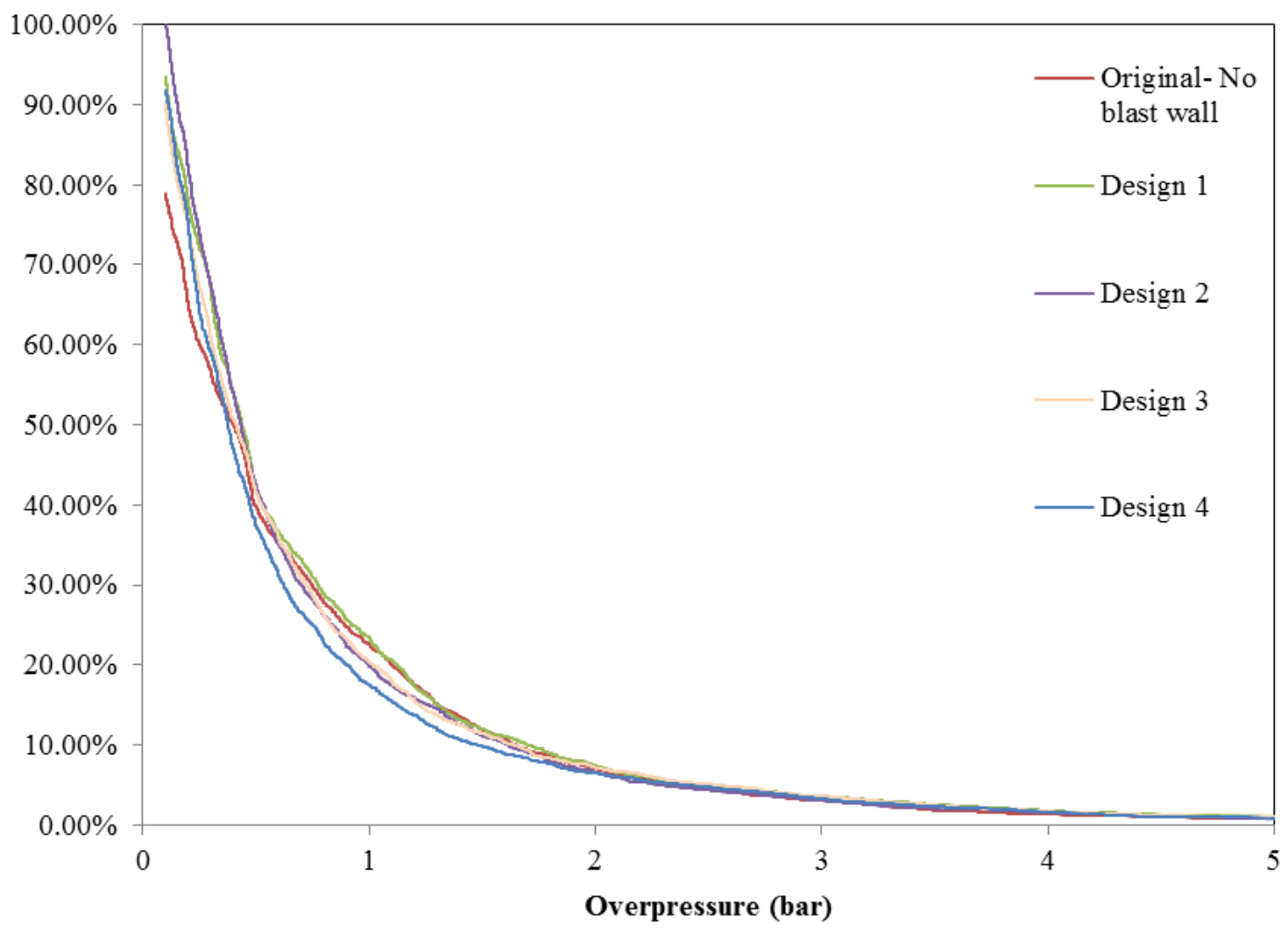

Figure 14 Exceedance curve of overpressures for all leak rate scenarios

Figure 14 shows the integral overpressure data for all blast wall designs. Regardless of the varying leak rate consequences, all blast wall layouts are detrimental in explosion mitigating if the resulting overpressures are below 0.3 bar. Whereas if the gas explosions result in overpressures over 0.3 bar, there are more than $50 \%$ possibilities that blast wall layout No.2, 3, 4 are beneficial to the integral structures, namely, all of the recorded overpressures can be mitigated by using blast walls. It is noted that the overpressures over 0.3 bar have already reach the detonation status of a gas explosion, which is more destructive to structures and personals, compared to the pressure obtained in deflagration stage. In other words, blast wall layouts of No. 2, 3, 4 here are efficient in gas explosion mitigating for gas explosions with detonation overpressures over 0.3 bar. Amongst the designs, the blast wall layout No. 4 with lowest exceedance frequencies in Figure 14 is the optimum. 
The individual exceedance curves of gas explosion overpressure resulted from all different leak rate scenarios are shown from Figure 15 to Figure 18. For leak rate of $12 \mathrm{~kg} / \mathrm{s}$, the gas dispersion simulations result in around $0.5 \times 10^{4} \mathrm{~m}^{3}$ averaged gas cloud size (Figure 10), which is less than one-tenth of that $\left(6 \times 10^{4} \mathrm{~m}^{3}\right)$ from the gas dispersion of leak rate $96 \mathrm{~kg} / \mathrm{s}$ (Figure 10). These small gas clouds generates explosion overpressures smaller than $0.1 \mathrm{bar}$ for all blast wall layouts as seen in Figure 15, and the overpressures obtained from the original cylindrical FLNG platform without blast walls are even too small to display. Therefore, an extra diagram inside Figure 15 is added.

Overall, the data of Figure 15 indicates that blast walls are not beneficial in overpressure reduction for the $12 \mathrm{~kg} / \mathrm{s}$ leak cases as the recorded overpressures of blast-wall cases are higher than that of no-blast-wall cases. However, the exceedance frequencies for all blast wall configurations are almost below $10 \%$ if overpressures are around 0.1 bar, which is below the threshold of 0.17 bar that causes distortion of steel frame structures, and 0.28 bar threshold of storage tank rupture pressure (Santamaría and Braña, 1998; Shariff et al., 2006; Lobato et al., 2009). For most cases that exceedance frequencies above 50\%, overpressures are even smaller than 0.05 bar. These smaller overpressures in low-leak-rate cases will have little impact on the offshore structures, which is not major concerns of this study.

In terms of the results of gas explosions for $24 \mathrm{~kg} / \mathrm{s}$ gas leak cases, obvious detrimental blast wall effect is seen in Figure 16 that overpressures in all layouts are higher than 0.2 bar, which are non-negligible and can cause partial demolition and collapse of wall structures (Lobato et al., 2009). Moreover, it is evident that all blast wall layouts result in higher overpressures than that in the original cylindrical FLNG without blast walls. 


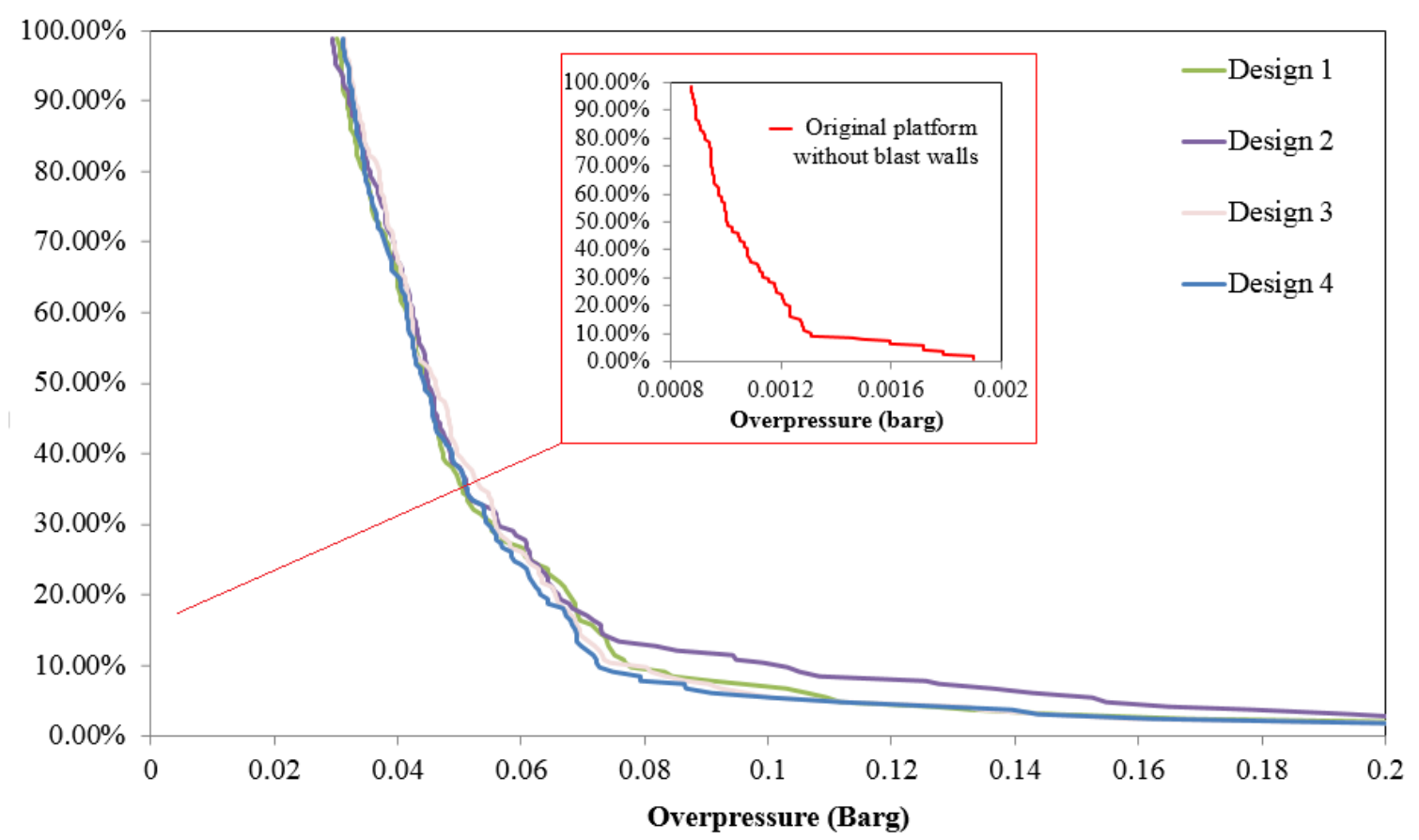

Figure 15 Exceedance curve of overpressures for leak rate at $12 \mathrm{~kg} / \mathrm{s}$

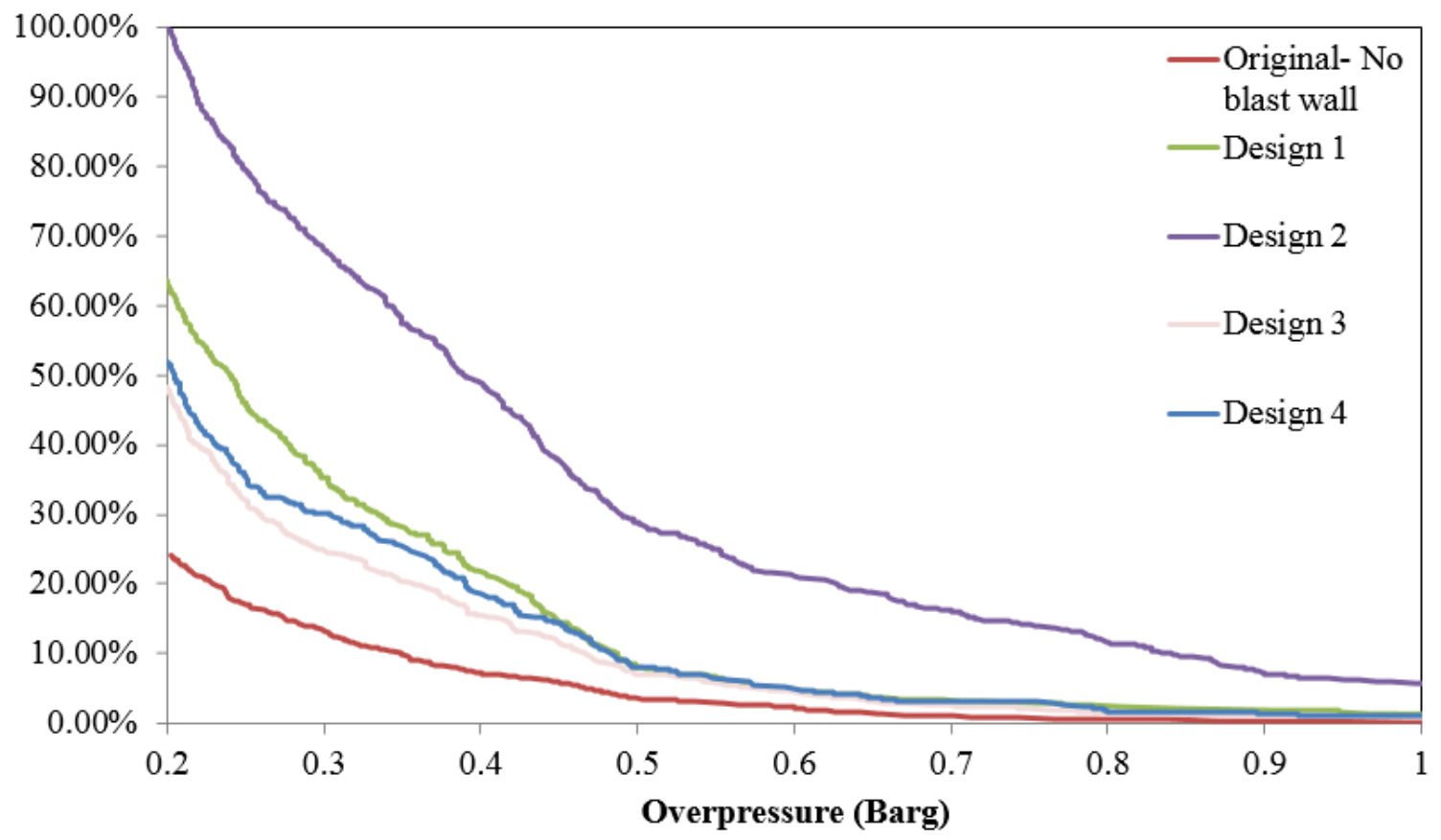

Figure 16 Exceedance curve of overpressures for leak rate at $24 \mathrm{~kg} / \mathrm{s}$

By contrast, the benefits of blast walls are seen in Figure 17 and Figure 18 where the gas clouds used in the gas explosion simulations are from leak rates of $48 \mathrm{~kg} / \mathrm{s}$ and $96 \mathrm{~kg} / \mathrm{s}$. It is shown in Figure 17 that blast wall layout No. 2 and No. 3 have slightly lower exceedance frequencies than the original configuration without blast walls, while blast wall layout No. 4 
shows its distinct advantage of overpressure mitigation that most of the overpressures in this design have much lower frequencies than others. Figure 18 further indicates the blast walls' benefits in explosion overpressure mitigating in the $96 \mathrm{~kg} / \mathrm{s}$ leak case. The overpressure mitigation efficiency is more obvious for blast wall layout No. 2 and No. 4. For instance, as seen in Figure 18, the exceedance probabilities of overpressures over 0.4 bar in the originally no-blast-wall platform significantly drop from $83 \%$ to $63 \%$ by using blast wall layout No. 2 and No. 4.

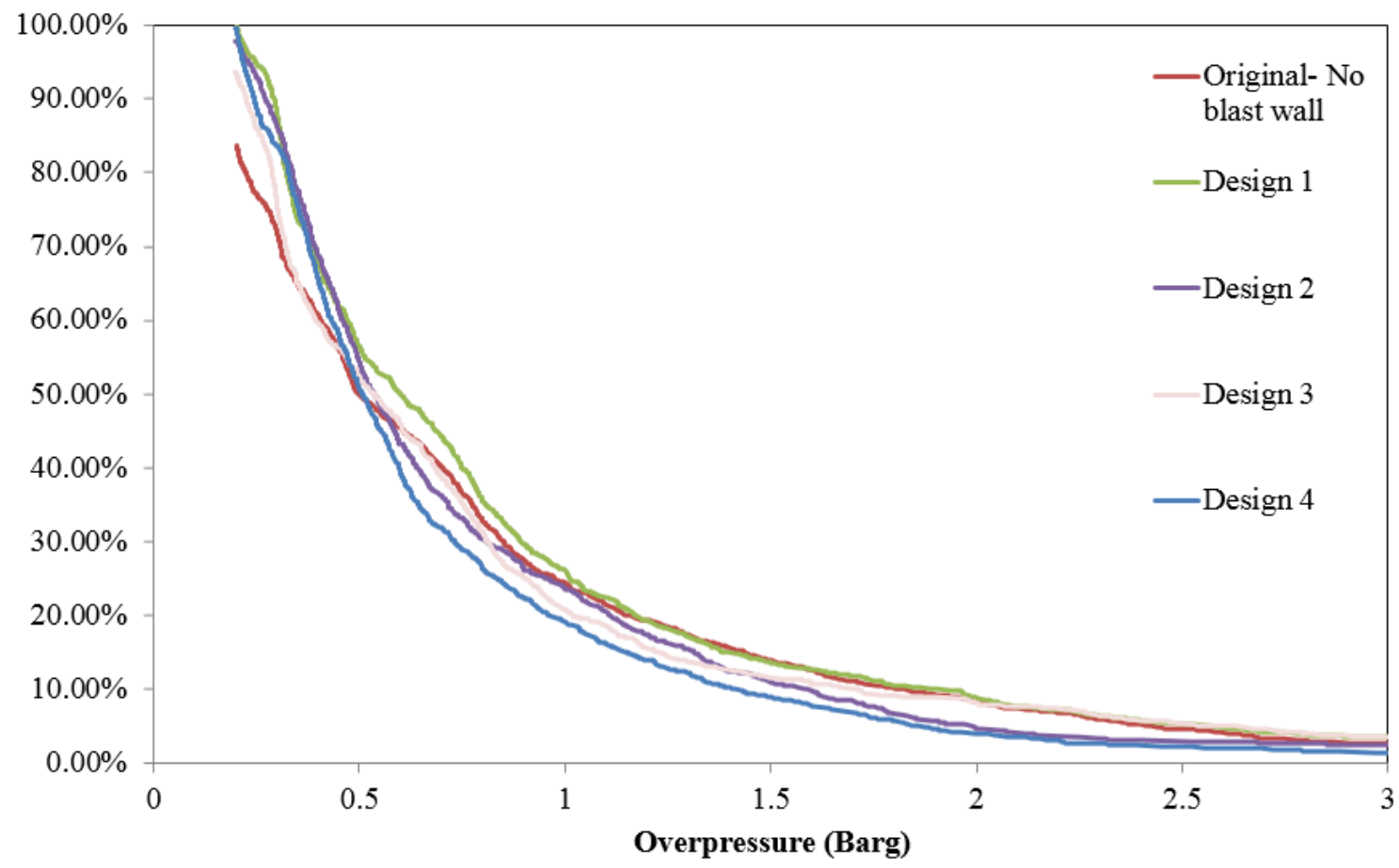

Figure 17 Exceedance curve of overpressures for leak rate at $48 \mathrm{~kg} / \mathrm{s}$ 


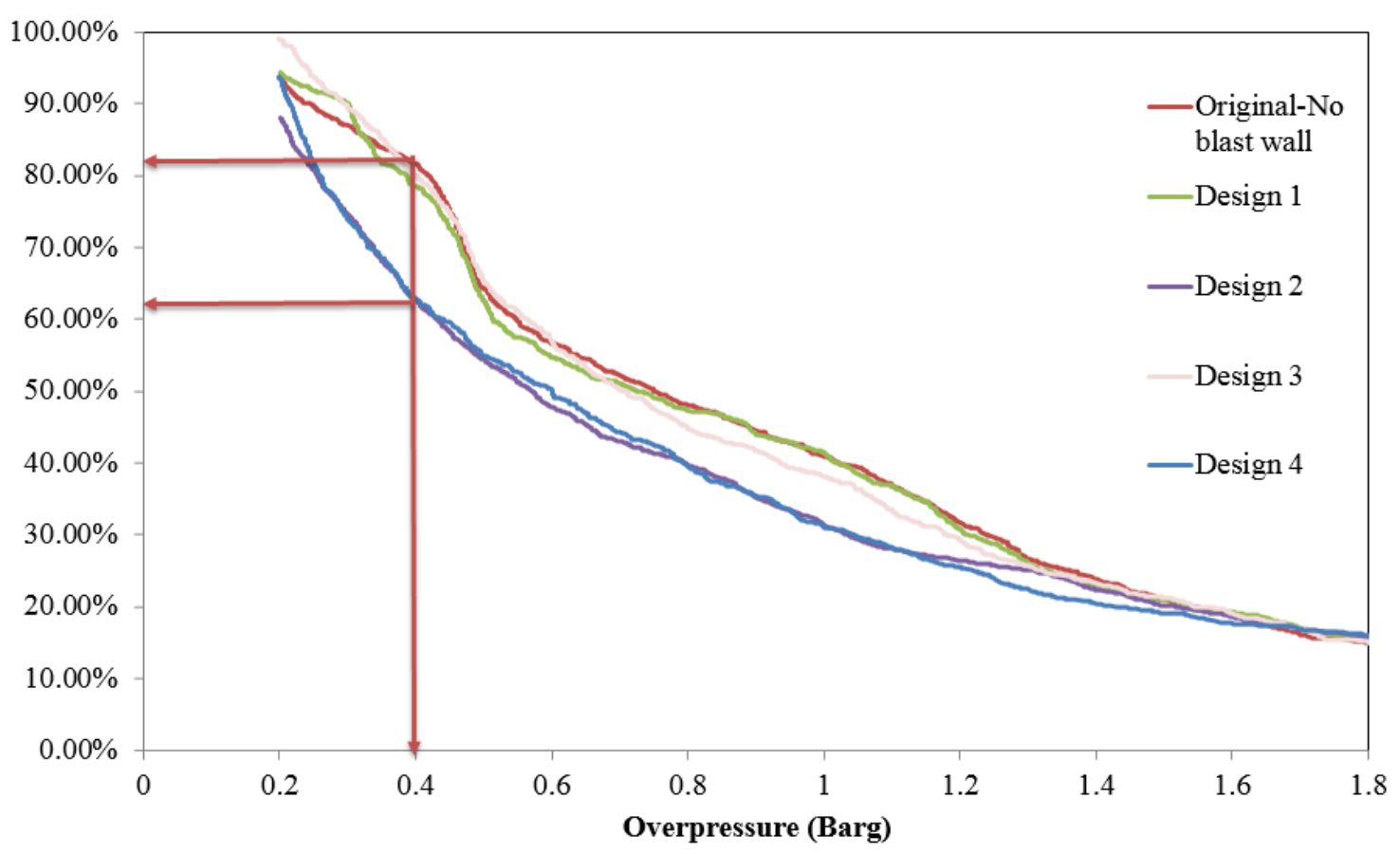

Figure 18 Exceedance curve of overpressures for leak rate at $96 \mathrm{~kg} / \mathrm{s}$

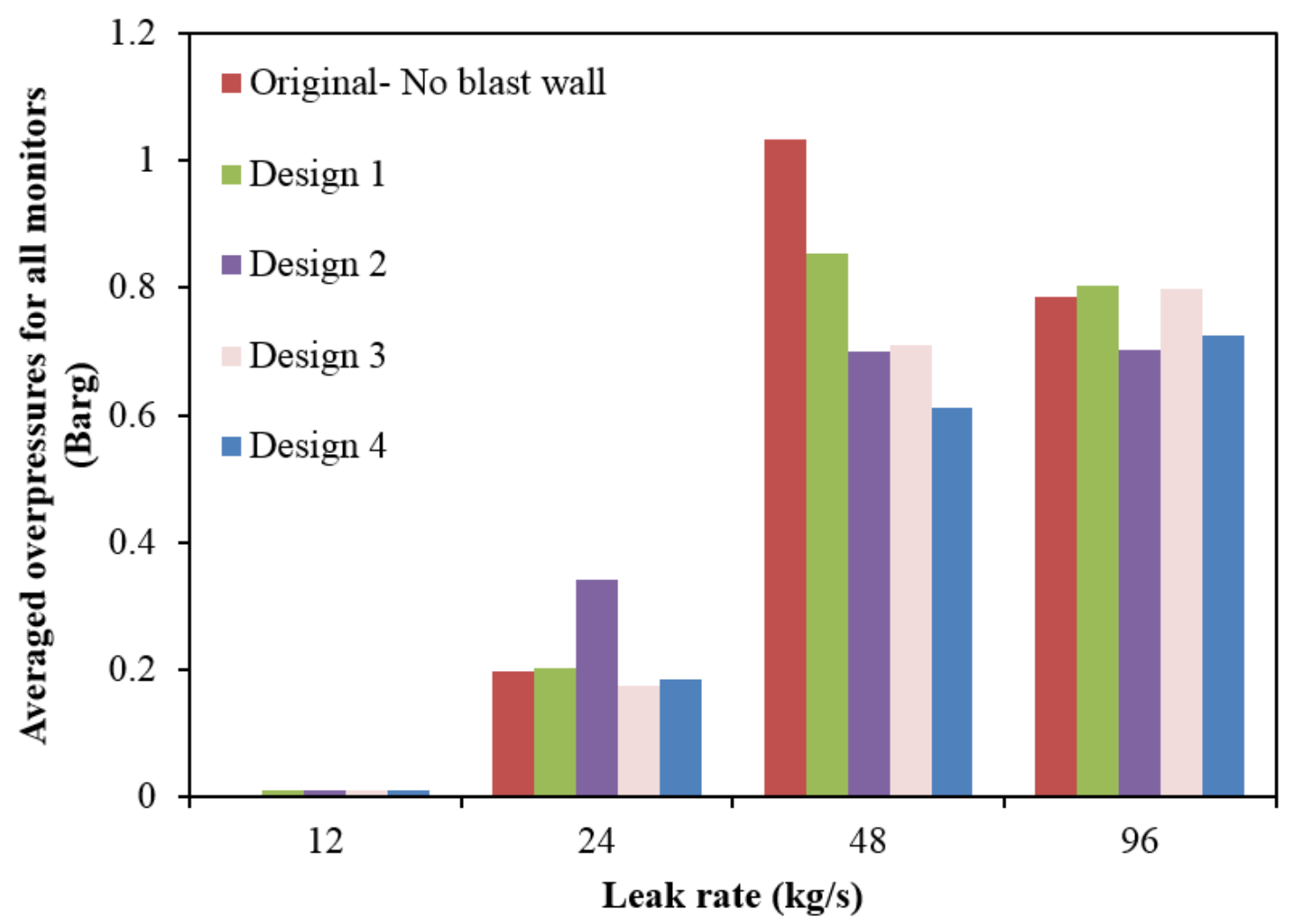

Figure 19 Averaged overpressures for different leak rate scenarios

Therefore, according to the exceedance curves above, it is concluded that blast walls are only effective in explosion mitigation for overpressures over the detonation status, blast wall 
layout No. 2 and No. 4 are particularly beneficial in overpressure mitigation for high leak rate scenarios. Additionally, Figure 19 compares all blast wall designs by averaging all monitored overpressures in all different leak rate scenarios. Although it is mentioned that blast wall layout No. 2 and No. 4 are the most effective blast wall designs for high leak rate gas releases, blast wall layout No. 2 surprisingly increased the averaged overpressures for the integral structure at leak rate of $24 \mathrm{~kg} / \mathrm{s}$, by contrast, blast wall layout No. 4 is consistent in overpressure mitigation under the same circumstance. Consequently, blast wall layout No. 4 is again approved to be the optimal design in the integral analysis of gas explosion.

\subsubsection{Investigation of the living quarter subjected to gas explosions}

In addition to the integral analysis of gas explosion, another major interest of this study is to investigate the protection target - living quarter, which is identified as it has the highest level of potential risks (Huang et al., 2016). In order to monitor the overpressures in the living quarter area, for each gas explosion scenario, 10 monitor points are assigned.

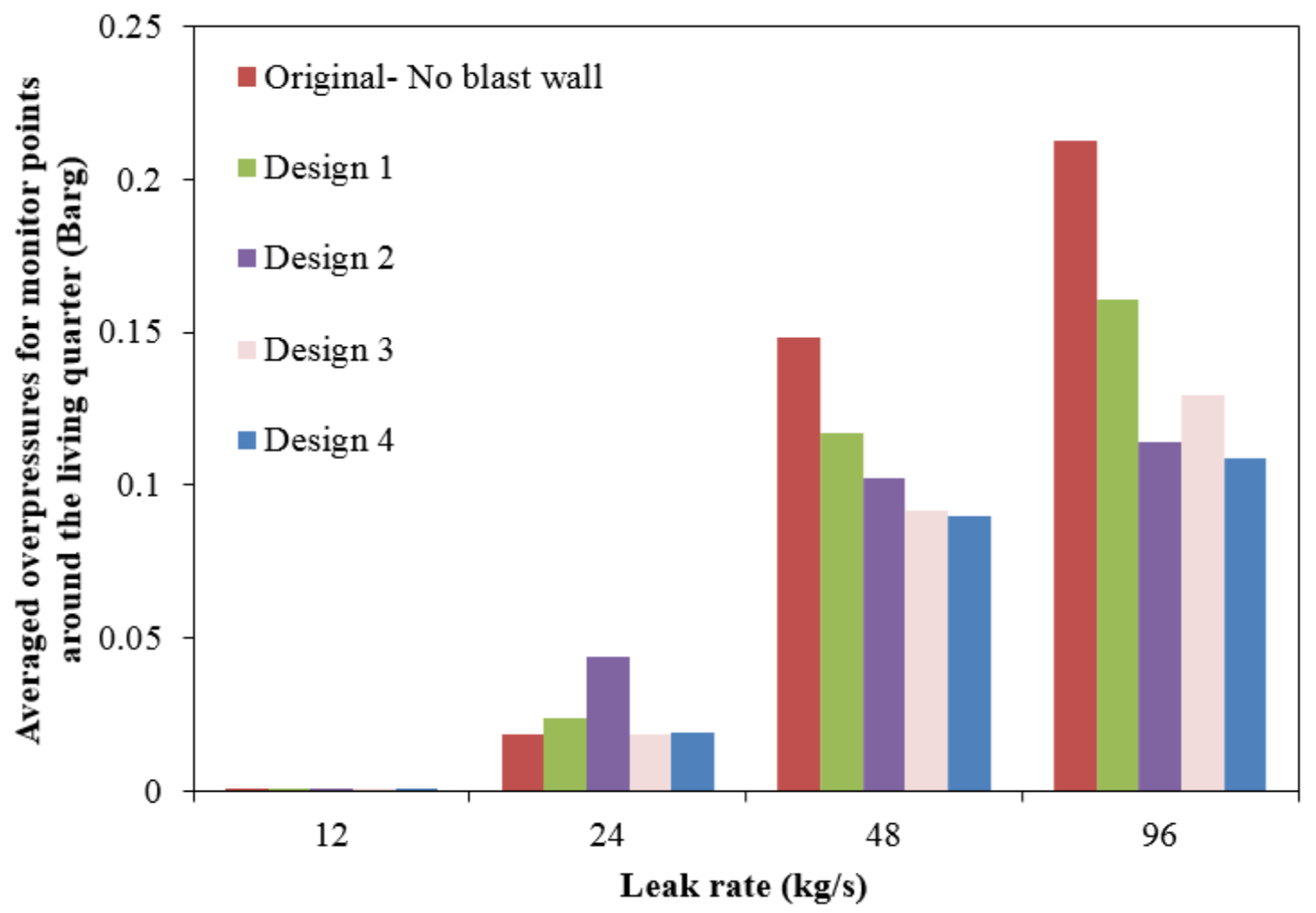


Figure 20 shows the averaged overpressures from all monitors around the living quarter in different leak rate scenarios. The similar overpressure mitigation effects of blast wall for large leak rate $(48 \mathrm{~kg} / \mathrm{s}$ and $96 \mathrm{~kg} / \mathrm{s})$ cases are seen. However, comparing to the overpressure mitigation in the integral structure in Figure 19, the blast wall layout No. 4 reduces more averaged overpressures around the living quarter at $96 \mathrm{~kg} / \mathrm{s}$ leakage case.

Furthermore, the detailed explosion frequency calculation is performed in this section. The exceedance frequency of overpressure at the living quarter are calculated by using the monitored overpressures over 1000 scenarios along with the leak frequencies and ignition probability determined previously (Gexcon, 2012).

Table 3 indicates the ignition intensities for all releases from $12 \mathrm{~kg} / \mathrm{s}$ to $96 \mathrm{~kg} / \mathrm{s}$ in this study. The exposed area in the CFD simulations is corresponding to the area on the vessel exposed to Equivalent Stoichiometric gas Cloud (ESC) from a release in the liquefaction module. The leak frequency is taken as $3.33 \times 10^{-1}$ per year according to the Guidelines for quantitative risk assessment Purple Book (Uijt and Ale, 2005). Based on the ignition intensities and the gas dispersion simulation results, the ignition probability is determined as $0.36 \%$. The explosion frequency is calculated by multiplying the leak frequency and ignition probability, therefore, the total explosion frequency is approximated as $1.2 \times 10^{-3}$ per year. 
Table 3 Discrete and continuous ignition intensities for releases (> $6 \mathrm{~kg} / \mathrm{s})$

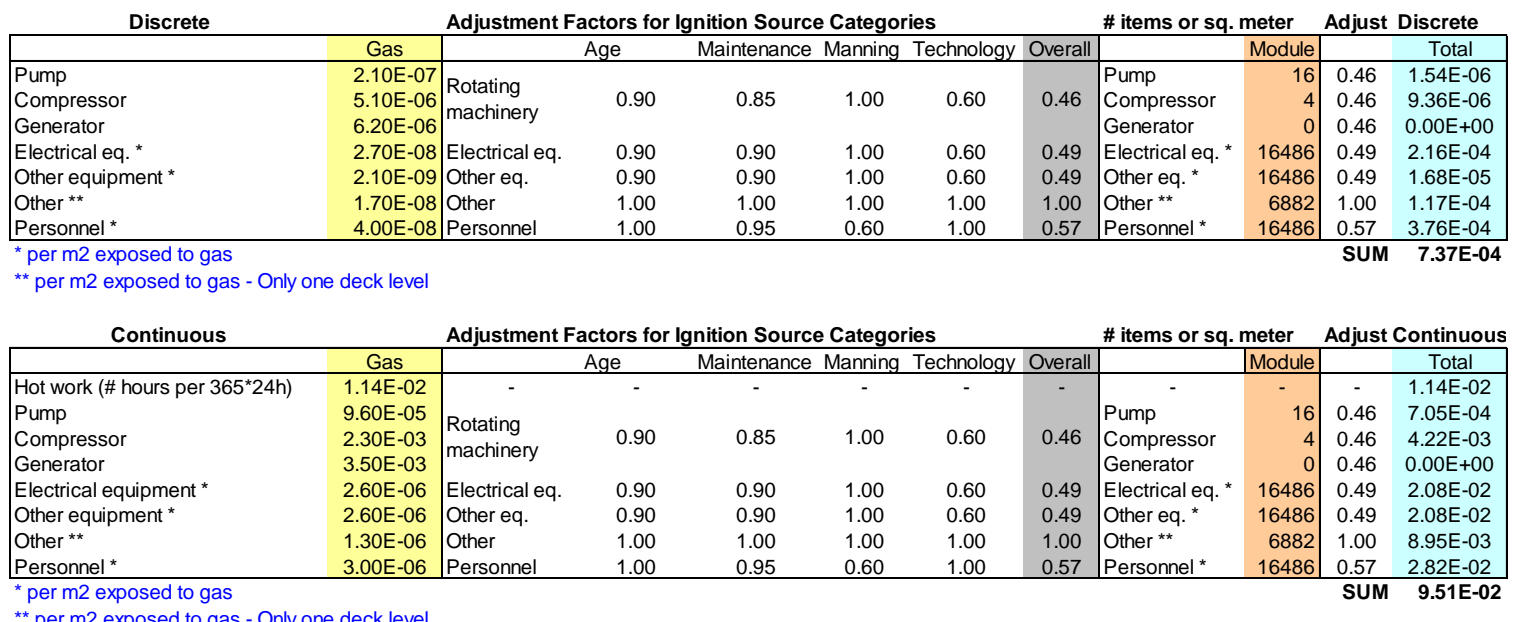

** per m2 exposed to gas - Only one deck level

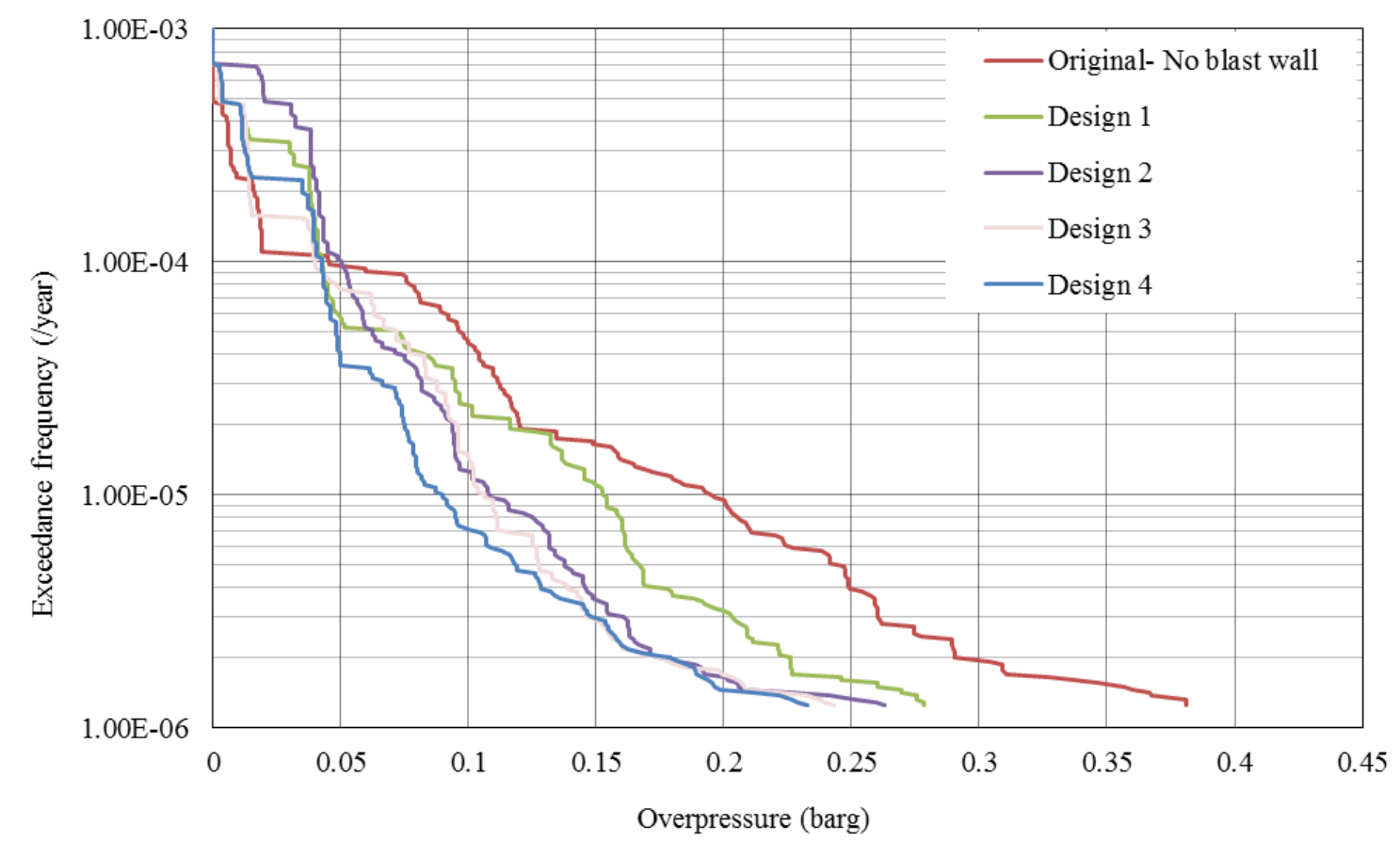

Figure 21 Exceedance curve of overpressures around the living quarter for all leak rate scenarios

By summarizing all gas explosion simulation data around the living quarter, the probability of exceedance curves with frequencies are shown in Figure 21. Unlike the integral overpressure distribution on the entire FLNG platform in Section 5.2.2.1, the leak frequency and ignition probability are considered in the explosion risk analysis on the specific target - the living quarter. For each investigation on the blast wall designs, the overpressure occurring frequencies can be read from Figure 21 and used as the index for engineers to choose the 
appropriate blast wall design more confidently. For example, for 0.1 bar explosion design, it is seen in Figure 21 that the overpressure exceedance frequency from the original platform greatly falls from $4.5 \times 10^{-5}$ per year to only $0.7 \times 10^{-5}$ per year by using the optimal blast wall design - layout No. 4. Overall, the explosion risk analysis in this paper provides a solid explosion design process and the optimization of blast walls by comparing data of overpressures and frequencies in the exceedance curves.

\section{Conclusion}

After investigating the safety gap effect on the cylindrical FLNG platform (Li et al., 2016a; Li et al., 2016b), another gas explosion mitigating measure - blast wall is studied in this paper. Both of deterministic and probabilistic studies on the blast wall layouts subjected to gas dispersion and gas explosion have been conducted. The gas dispersion and gas explosion simulations are performed by using CFD-based software - FLACS.

In the previous investigation of the cylindrical FLNG platform, safety gaps were placed in North-South direction as the minimum required open space was sufficient exclusively in this direction to interrupt the propagation of flammable gas and explosion overpressure (Li et al., 2016a; Li et al., 2016b). However, the space between two adjacent modules in East-West direction is limited. Therefore in this study, blast walls, which can be installed very close to protecting modules to control and mitigate excessive overpressure loading, are installed in the East-West direction to address the space limitation issue. Four sets of different blast wall layouts plus the original no-blast-wall FLNG platform are modelled in FLACS.

Firstly, over 120 gas dispersion simulations with variables including 4 different leak rates, 3 different leak locations, 2 different leak orientations, and 5 layouts with and without blast walls, are carried out. The results indicate that all blast wall designs are not beneficial for reducing stoichiometric gas cloud size if the leakage rate is equal or below $24 \mathrm{~kg} / \mathrm{s}$, while 
mitigation effect of blast wall is exclusively seen for blast wall layout No. 2 and No. 4 in large rate scenarios ( leak rate $>24 \mathrm{~kg} / \mathrm{s}$ ).

Subsequently, the investigation of gas explosions with over 3200 scenarios for each blast wall design scheme is performed, all gas cloud results from gas dispersion simulations are used as the input in the explosion simulations. The gas explosion analysis includes both of the integral study of all blast wall layouts on the cylindrical FLNG topside and individual safety study on the living quarter, which has the highest level of potential risks (Huang et al., 2016).

Globally, similar to the controversial results seen in gas dispersion simulations, overpressures recorded on the integral FLNG platform with blast walls are enhanced in lowleak-rate $(12 \mathrm{~kg} / \mathrm{s}$ and $24 \mathrm{~kg} / \mathrm{s})$ scenarios, while blast wall only plays positive role in explosion overpressure mitigating in high-release-rate $(48 \mathrm{~kg} / \mathrm{s}$ and $96 \mathrm{~kg} / \mathrm{s})$ cases. It is worth noting that overpressures in low-leak-rate scenarios are with low possibilities (e.g. below $10 \%)$ and below the thresholds of destructive overpressures $(\sim 0.1$ bar $)$ to fundamental offshore structures, which are nearly negligible in offshore structural response study. However, a certain level reduction of overpressures (i.e. >1 bar) by using blast wall in highrelease-rate scenarios can significantly improve structure's safety. The results from the integral analysis of gas explosion in high-release-rate scenarios show that more blast walls mitigate more overpressures on the entire FLNG platform. Amongst all blast wall layouts, No. 4 blast wall layout is the most ideal design that blast walls considerably decrease the overpressures by more than $20 \%$ in high-release-rate $(96 \mathrm{~kg} / \mathrm{s})$ scenario.

Locally, for the living quarter, the layout optimization of blast wall is further conducted by summarizing explosion overpressure frequencies in the probabilistic study. The leak frequencies and ignition probabilities are taken into account. The exceedance curves of 
overpressures for the living quarter have further validated the effectiveness of overpressure mitigation by using blast walls. Especially, the optimum design of blast wall layout No. 4 can reduce more than $80 \%$ of the overpressure exceedance frequency (e.g. $4.5 \times 10^{-5}$ per year to $0.7 \times 10^{-5}$ per year ) for a safety design with maximum overpressures of 0.1 bar in the living quarter.

To sum up, the optimization of the blast wall layout on the cylindrical FLNG platform has been carried out globally and locally. The results from the gas dispersion and gas explosion analysis indicate that blast wall, which requires little installation space, is an optimal alternative to safety gap to mitigate flammable gas cloud and gas explosion overpressures, particularly in high-leak-rate and space-limited scenarios. Comparing to the worst-scenario study conducted previously, the probabilistic study in this paper has considered more uncertainties and delivers more convincing CFD simulation data. Moreover, this paper provides a comprehensive safety evaluation procedure for engineers to design the gas dispersion and gas explosion mitigation system - blast wall layout on a cylindrical FLNG platform. 


\section{References}

Black\&Veatch. 2016. Floating liquefied natural gas. https://en.wikipedia.org/wiki/Floating_liquefied_natural_gas.

Boh, J., Louca, L.A., Choo, Y., 2007. Finite Element Analysis of Blast Resistant Structures in the Oil and Gas Industry.

Daubech, J., Proust, C., Gentilhomme, O., Jamois, C., Mathieu, L., 2013. Hydrogen - air vented explosion: new experimental data. Proc. of 5th ICHS, Brussels.

Gexcon. 2012. FLNG Concept Explosion Study - Explosion Risk Analysis. Ref. No.: GexCon-2011-F40836-RA-01.

Gexcon. 2015. FLACS v10.4 User's Manual (Doxygen: Norway).

Hansen, O.R., Gavelli, F., Ichard, M., Davis, S.G., 2010. Validation of FLACS against experimental data sets from the model evaluation database for LNG vapor dispersion. J Loss Prevent Proc. 23 (6), 857-77.

Hansen, O.R., Johnson, D.M., 2015. Improved far-field blast predictions from fast deflagrations, DDTs and detonations of vapour clouds using FLACS CFD. J Loss Prevent Proc. 35, 293-306.

Hetland, J., Kvamsdal, H.M., Haugen, G., Major, F., Karstad, V., Tjellander, G., 2009. Integrating a full carbon capture scheme onto a 450 MWe NGCC electric power generation hub for offshore operations: Presenting the Sevan GTW concept. Appl Energ. 86 (11), 2298-307.

HSE. 2006. Structural strengthening of offshore topsides structures as part of explosion risk reduction methods. In Research Report 489. UK: Health \& Safety Executive

Huang, Y.M., Ma, G.W., Li, J.D., Hao, H., 2016. Multi-level explosion risk analysis (MLERA) for accidental gas explosion events in super-large FLNG facilities. $J$ Loss Prevent Proc. In Press.

Kang, K.-Y., Choi, K.-H., Choi, J., Choi, Y., Choi, J.-M., 2016. Explosion induced dynamic responses of blast wall on FPSO topside: Blast loading application methods International Journal of Naval Architecture and Ocean Engineering. In Press.

Kuznetsov, M., Friedrich, A., Stern, G., Kotchourko, N., Jallais, S., L'Hostis, B., 2015. Medium-scale experiments on vented hydrogen deflagration. J Loss Prevent Proc. 36, 418-30.

Langdon, G.S., Schleyer, G.K., 2005. Inelastic deformation and failure of profiled stainless steel blast wall panels. Part I: experimental investigations. Int J Impact Eng. 31 (4), 341-69.

Langdon, G.S., Schleyer, G.K., 2006. Deformation and failure of profiled stainless steel blast wall panels. Part III: finite element simulations and overall summary. Int J Impact Eng. 32 (6), 988-1012.

Li, J.D., Abdel-jawad, M., Ma, G.W., 2014. New correlation for vapor cloud explosion overpressure calculation at congested configurations. J Loss Prevent Proc. 31, 16-25.

Li, J.D., Ma, G.W., Abdel-Jawad, M., Huang, Y.M., 2016a. Gas dispersion risk analysis of safety gap effect on the innovating FLNG vessel with a cylindrical platform. J Loss Prevent Proc. 40, 304-16.

Li, J.D., Ma, G.W., Hao, H., Huang, Y.M., 2016b. Gas explosion analysis of safety gap effect on the innovating FLNG vessel with a cylindrical platform. J Loss Prevent Proc. 44, 263-74. 
Lobato, J., Rodriguez, J.F., Jimenez, C., Llanos, J., Nieto-Marquez, A., Inarejos, A.M., 2009. Consequence analysis of an explosion by simple models: Texas refinery gasoline explosion case. Afinidad. 66 (543), 372-79.

Louca, L.A., Boh, J.W., Choo, Y.S., 2004. Design and analysis of stainless steel profiled blast barriers. Journal of Constructional Steel Research. 60 (12), 1699-723.

Louca, L.A., Punjani, M., Harding, J.E., 1996. Non-linear analysis of blast walls and stiffened panels subjected to hydrocarbon explosions. Journal of Constructional Steel Research. 37 (2), 93-113.

Naciri, M., Waals, O., de Wilde, J., 2007. Time domain simulations of side-by-side moored vessels lessons learnt from a benchmark test. Proceedings of the 26th International Conference on Offshore Mechanics and Arctic Engineering, Vol 1, 801-11.

Norsok. 2001. Norsok Standard - Risk and emergency preparedness analysis Z-013 (Norway: Norwegian Technology Centre).

Santamaría, J.M., Braña, P.A., 1998. Risk analysis and reduction in the chemical process industry (Blackie academic Professional, London).

Schleyer, G.K., Lowak, M.J., Polcyn, M.A., Langdon, G.S., 2007. Experimental investigation of blast wall panels under shock pressure loading. Int J Impact Eng. 34 (6), 1095-118.

Shariff, A.M., Rusli, R., Leong, C.T., Radhakrishnan, V.R., Buang, A., 2006. Inherent safety tool for explosion consequences study. J Loss Prevent Proc. 19 (5), 409-18.

Shell-Global. 2016. Prelude FLNG - overview. http://www.shell.com/about-us/majorprojects/prelude-flng/prelude-flng-an-overview.html.

Silvestrini, M., Genova, B., Trujillo, F.J.L., 2008. Correlations for flame speed and explosion overpressure of dust clouds inside industrial enclosures. J Loss Prevent Proc. 21 (4), 374-92.

Sohn, J.M., Kim, S.J., Kim, B.H., Paik, J.K., 2013. Nonlinear structural consequence analysis of FPSO topside blastwalls. Ocean Engineering. 60, 149-62.

Songhurst, B., 2016. Floating Liquefaction (FLNG): Potential for Wider Deployment (University of Oxford).

Suardin, J.A., McPhate, A.J., Sipkema, A., Childs, M., Mannan, M.S., 2009. Fire and explosion assessment on oil and gas floating production storage offloading (FPSO): An effective screening and comparison tool. Process Saf Environ. 87 (3), 147-60.

Syed, Z.I., Mohamed, O.A., Rahman, S.A., Non-linear Finite Element Analysis of Offshore Stainless Steel Blast Wall under High Impulsive Pressure Loads Procedia Engineering. 145, 1275-82.

Uijt, P.A.M., Ale, B.J.M., 2005. Guidelines for quantitative risk assessment. Ministerie van Verkeer en Waterstaat, VROM.

Vyazmina, E., Jallais, S., 2016. Validation and recommendations for FLACS CFD and engineering approaches to model hydrogen vented explosions: Effects of concentration, obstruction vent area and ignition position. Int J Hydrogen Energ. 41 (33), 15101-09.

White, J., Longley, H., 2009. FLNG technology shows promise for stranded gas fields. Offshore. 69 (11), 78-79. 